Review Article

\title{
Processing Methods and Mechanical Properties of Aluminium Matrix Composites
}

\author{
Gebre Fenta Aynalem \\ Mechanical Engineering, Addis Ababa Science and Technology University, Addis Ababa 16417, Ethiopia \\ Correspondence should be addressed to Gebre Fenta Aynalem; gebre.fenta@aastu.edu.et
}

Received 26 May 2020; Revised 31 August 2020; Accepted 5 September 2020; Published 18 September 2020

Academic Editor: Stefano Bellucci

Copyright (c) 2020 Gebre Fenta Aynalem. This is an open access article distributed under the Creative Commons Attribution License, which permits unrestricted use, distribution, and reproduction in any medium, provided the original work is properly cited.

\begin{abstract}
Processing methods of aluminium matrix composites (AMCs) have been changing continuously considering the ease of manufacturing and the final quality of the desired composite. The most well-known processing techniques of AMCs such as stir casting, powder metallurgy, spark plasma sintering, squeeze casting, friction stir processing, liquid metal infiltration, spray codeposition, and reactive in situ techniques have elaborated here with their respective distinguishing features and mechanical properties of the fabricated composites. Moreover, this review paper contains the factors affecting the mechanical properties of AMCs as well as their clear justifications. The mechanical properties of AMCs are highly affected by the type of processing method, process parameters, and type, size, and composition of the reinforcing material. Concerning this, the mechanical properties of aluminium and its alloys are highly improved by adding a variety of reinforcing materials in a broader spectrum.
\end{abstract}

\section{Introduction}

Metal matrix composites (MMCs) are advanced materials, which combine the property of tough metallic matrix material like aluminium with the hard ceramic reinforcement to produce composite having extraordinary material properties. MMCs have been studied for some years, and their potential advantages over conventional monolithic alloys are increasingly being appreciated [1]. The increasing demands for lightweight, high specific strength, excellent high-temperature performance, exceptional corrosion resistance, chemically inert, and energy-saving materials in the transportation, agriculture, construction, and manufacturing industries have stimulated a steadily growing activity to develop specific composite materials called aluminium matrix composites (AMCs). They are lightweight and highperformance materials that have the potential to replace conventional materials in many advanced applications [2]. AMCs have been gaining importance due to their higher strength and stiffness, increased wear resistance, increased hardness without a significant change in ductility, improved compressive strength, decreased thermal conductivity, and improved dimensional stability. These and other characteristics make AMCs preferable in the field of aerospace, automobiles, marine, medical, electronic packaging, and home appliances in a broader spectrum [3-6].

Research works show that both the liquid-phase and solid-phase fabrication methods have been used to make AMCs to their desired size and shape which has a significant effect in determining their mechanical property. For example, AMCs reinforced with ceramic particles such as $\mathrm{SiC}$, $\mathrm{Al}_{2} \mathrm{O}_{3}, \mathrm{Y}_{2} \mathrm{~W}_{3} \mathrm{O}_{12}$, and $\mathrm{AlN}$, with soft metallic materials such as $\mathrm{Cu}$ and high carbon steel chips powder, and with soft nonmetallic materials such as fly ash (FA) and aloe vera (AV) powder particles exhibit better mechanical properties than the unreinforced aluminium alloys. Besides, the material properties of AMCs can be enhanced by a cryogenic treatment which is advantageous since it is a low cost, simple, environmentally friendly, and nondestructive operation $[3,4,7-11]$. However, problems arising from the inappropriate selection of processing methods, manufacturing techniques, incorrect selection of processing parameters (type, content, and particle size of the reinforcement and melting and sintering temperatures), and inappropriate selection of secondary manufacturing processes are broadly the possible difficulties encountered to get 
AMCs which are free of defects. And in this review paper, various kinds of processing methods of AMCs and their respective mechanical properties have been discussed in detail. Moreover, a clear discussion of processing parameters and result attributes has also been elaborated in depth based on their research outcomes.

\section{Processing Methods of AMCs}

Fabrication processes used for different MMCs depend on parameters such as type and composition of matrix and reinforcement martial, wettability and uniform distribution of reinforcing particle in the base matrix, and production cost. According to the operational conditions, the fabrication processes of aluminium-based composites have been categorized into two types which are liquid-state fabrication and solid-state fabrication processes [12]. In liquid-state fabrication, the matrix material is heated above its liquefaction temperature and the reinforcement has been added into the molten matrix which has been aluminium and its alloys in aluminium-based composites. And, under this, stir casting, infiltration processes, squeeze casting, reactive in situ technique, and spray codeposition have been discussed well. In solid-state fabrication processes, the reinforcement material is introduced and mixed throughout the matrix body in the solid state. And the corresponding fabrication processes such as solid-state powder metallurgy, spark plasma sintering (SPS), and friction stir processing (FSP) are discussed here as well.

2.1. Stir Casting. Stir casting is a technique used for composite material fabrication when reinforcing materials ( $\mathrm{SiC}$ and $\mathrm{Cu}$, high carbon steel chips, FA and AV powder particles, etc.) are mixed with an aluminium matrix with the help of a stirrer driven manually or automatically. The stir casting technology is comparatively simple and low cost for the fabrication of AMCs than its alternatives which can be easily adopted in various industries [3]. The molten composite melt will be cast by the traditional casting method; matrix material will be heated above its melting point, so metal is melted and stirrer will start rotating. Then, the raw or preheated reinforcement material will be added slowly to the vortex, and after some time, the molten composite melt will be poured into the mould and wait for it to solidify. Moreover, Figure 1 shows how the conventional stir casting process looks like which is utilized generally to prepare MMCs [13]. The main drawback of this technique is that the distribution of the reinforcement material in the matrix may not completely homogeneous [14]. The interfacial reactions between metallic particles and molten aluminium are unavoidable and form a significant amount of intermetallic in the composite. Also, there may be the existence of some agglomerates due to density differences and the formation of porosity which lessens the material property of the composite. And, this can be avoided or minimized by using several methods such as double-step stir casting [15-17], adding wettable elements such as magnesium, applying secondary operations such as forging, extrusion, and heat treatment processes [18-22], or setting optimum processing parameters such as composition, stirring speed, casting temperature, stirrer blade angle, and stirring time which is going to be discussed here.

Related to this, AMCs were manufactured using AA6061 as a matrix and preheated $15 \mathrm{wt} \% \mathrm{TiC}$ reinforcement particles by the stir casting process. The study intended to improve the ultimate tensile strength (UTS) of the base matrix using ceramic particulates by changing the parameters (stirring speed, stirring time, angle of the stirrer, and casting temperature) and to identify the optimum processing parameters which bring the maximum ultimate strength of the composite. $2 \mathrm{wt} \% \mathrm{Mg}$ and argon gas were added for wettability and to avoid oxide formation of the composite samples. In doing so, the optimum parameters (stirring speed of $300 \mathrm{rpm}$, stirring time of $15 \mathrm{~min}$, stirrer blade angle of $30^{\circ}$, and casting temperature of $830^{\circ} \mathrm{C}$ ) were set for AA6061/15\% TiC composites attaining a maximum UTS of $240 \mathrm{MPa}$ [23]. A research was done using Al2014 matrix and $5 \% \mathrm{SiC}$ reinforcement powder to identify the wear resistance and hardness of the composite. Al2014 matrix was heated to $600^{\circ} \mathrm{C}$, and $\mathrm{SiC}$ reinforcements preheated to $500^{\circ} \mathrm{C}$ for 45 minutes have been incorporated into the melt. Test results show that there were less wear loss and enhanced hardness with increasing $\mathrm{SiC}$ particles for composite specimens than the matrix alone. High hardness values were attributed as the $\mathrm{SiC}$ particles will hinder the motion of dislocation, hardening the composite [24]. Accordingly, $\mathrm{Al}-\mathrm{Zn}$ alloy and $\mathrm{FA} / \mathrm{SiC}$ particles as reinforcement were used to identify the mechanical behaviour of the composite by varying the composition of the reinforcing particles up to $15 \%$ using the stir casting route. A stirring speed of $450 \mathrm{rpm}$ was selected for uniform dispersion of reinforcing particles in the composite melt by using argon gas to eliminate oxidation of the alloy and the composite. And after fabrication, homogenization of the specimens was applied at $100^{\circ} \mathrm{C}$ for 24 hours. The Vickers hardness test shows that composites containing $10 \mathrm{wt} \% \mathrm{FA} / \mathrm{SiC}$ reinforcements have higher hardness than the base matrix alone. This improvement was attributed since rigid $\mathrm{Al}_{2} \mathrm{O}_{3}$ and $\mathrm{Si}$ exist in the $\mathrm{FA}$ and $\mathrm{SiC}$ reinforcements. Also, there was a rise in UTS, yield strength, and modulus of elasticity with increasing the hybrid $10 \mathrm{wt} \% \mathrm{FA} / \mathrm{SiC}$ reinforcements. The reason was ascribed due to the existence of particles with little elasticity that are hard in their quality [25]. In the same manner, hybrid SiC/FA reinforcing particles with $2.5,5$, and $7.5 \mathrm{wt} \%$ of $\mathrm{SiC}$ and 2.5, 5, and 7.5wt\% of FA with Al6082 metal matrix were prepared by a stir casting process. The composite melt was poured at a temperature of $725^{\circ} \mathrm{C}$. Their test result depicts that there was an improvement in UTS, hardness, and wear resistance with increasing SiC and FA contents in the matrix. Besides, micrograph images show that the distribution of FA was somehow nonuniform in the composite [14]. On the other hand, hybrid $\mathrm{SiC} / \mathrm{Cu}$ particles were used as a reinforcement with a pure aluminium base matrix. $\mathrm{SiC}$ with 3,6 , and $9 \mathrm{wt} \%$ and $\mathrm{Cu}$ with $0.5,0.75$, and $1 \mathrm{wt} \%$ were used to fabricate the composite with the stir casting route. $\mathrm{SiC}$ particles were preheated at a temperature of $720^{\circ} \mathrm{C}$ for 20 minutes. During the process, the composite 


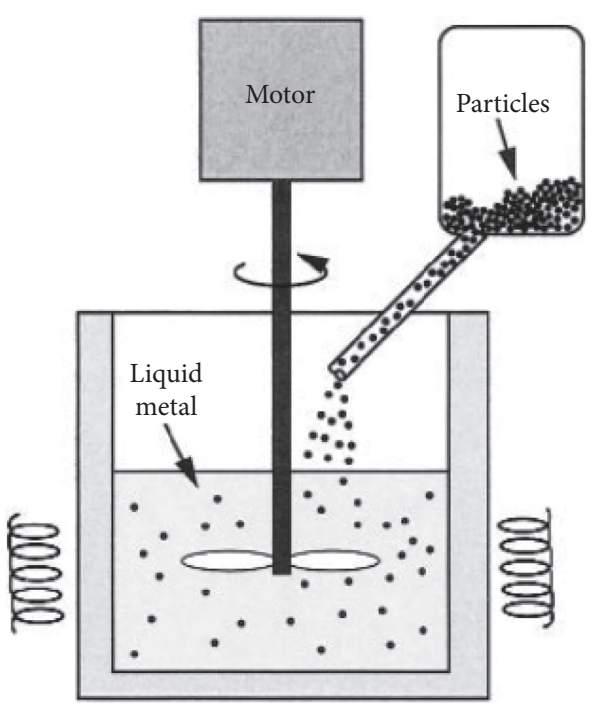

FIGURE 1: Stir casing setup used for the manufacturing of MMCs [13].

melt was stirred for 20 minutes to distribute the reinforcing particles uniformly in the matrix. Finally, their test result depicts that the higher weight percentage of reinforcements, less load, sliding distance, and speed results in a minimal wear loss of the composite [7].

FA particles, which are strong, hard, and low cost, were used to reinforce aluminium matrix. FA particles with the ratio of 2,4 , and $6 \mathrm{wt} \%$ were used to reinforce aluminium matrix by using the stir casting route. The matrix was heated and melted to a temperature of about $900^{\circ} \mathrm{C}$. This temperature was higher than the melting temperature depicted in other works of literature. The reason was to avoid the agglomeration of FA particles. The composite was mixed and stirred at a speed of $100 \mathrm{rpm}$. And wear test results of the study indicate that composites containing high FA particles have greater capacity in resisting wear than the composites with a lower amount of FA particles [26]. Similarly, FA powder $(40 \mathrm{~g})$ was used with $400 \mathrm{~g}$ of aluminium matrix, and mechanical property test results were compared with $40 \mathrm{~g}$ of AV powder with reinforced AMCs. FA powders were preheated at $100^{\circ} \mathrm{C}$ for 3 hours. The matrix was melted to $720^{\circ} \mathrm{C}$, and $1.5 \mathrm{wt} \% \mathrm{Mg}$ for $\mathrm{FA}$ and $3 \mathrm{wt} \% \mathrm{Mg}$ for $\mathrm{AV}$ were added to enhance wettability. The composite melt was stirred at $300 \mathrm{rpm}$ for 5 minutes. Mechanical property test results show that FA reinforcements have higher UTS and yield strength than AV powder reinforced composites, lower $\mathrm{BHN}$ value and impact strength capacity than AV powder reinforcement, and almost similar wear resistance capacity of both reinforcements. Moreover, micrograph images show that AV particles have dispersed more consistently. The distribution of AF powder particles and good bonding between matrix and AV powder were observed [10].

AMCs have also been fabricated by stir casting route using $\mathrm{Al}_{2} \mathrm{O}_{3}$ particles; mechanical and surface micrograph properties were determined. Evident to this, nano- $\mathrm{Al}_{2} \mathrm{O}_{3}$ particle reinforcements with $0.75,1.5,2.5,3.5$, and $7.5 \mathrm{vol} \%$ were used with the A353 aluminium alloy. The alloy was melted to $800^{\circ} \mathrm{C}$ and stirred for 15 minutes at a speed of $600 \mathrm{rpm}$. The test results of the study indicate that there was a higher volume percent of porosity with increasing the volume fraction of nano- $\mathrm{Al}_{2} \mathrm{O}_{3}$ particles. And at the beginning, with increasing the volume fraction of nano- $\mathrm{Al}_{2} \mathrm{O}_{3}$ particles, an increase in both UTS and yield strength was observed followed by a decrease in these properties, approximately when the volume fraction of nano- $\mathrm{Al}_{2} \mathrm{O}_{3}$ particles is greater than $2 \%$. The increase was attributed due to the uniform dispersion of nano- $\mathrm{Al}_{2} \mathrm{O}_{3}$ reinforcing particles, grain refinement, and greater multidirectional thermal stresses at the interface of $\mathrm{Al} / \mathrm{Al}_{2} \mathrm{O}_{3}$ composite. Also, the hardness of the composite was tested and revealed that it was increased with increasing the volume percent of $\mathrm{Al}_{2} \mathrm{O}_{3}$ particles up to $2.5 \%$. The reason for this was the reinforcing particles hinder the movement of dislocation by acting as an obstacle [27].

Secondary processes such as extrusion may also be used after the stir casting process to get AMCs having extraordinary properties. Relevant to this, the composite was fabricated using $10 \mathrm{wt} \%$ angular formed $\mathrm{Al}_{2} \mathrm{O}_{3}$ reinforcement (with a particle dimension of 6 to $18 \mu \mathrm{m}$ ) with the AA6061 matrix to study the wear resistance. The composites were first fabricated by direct chill casting and then hot extrusion process. The objective of the study was to identify the effect of sliding distance, pressure, and sliding speed on the wear resistance behaviour of the base matrix and the composite. Each testing parameter was changed by holding others fixed. Taking these into account, the effect of sliding distance on the wear resistance was done at a pressure of $0.14 \mathrm{MPa}$ and a sliding speed of $230 \mathrm{rpm}$. Test results of this illustrate that nearly a twice improvement in wear resistance capacity of the composite was gained as compared to the base matrix alone. The Archard wear equation was used to validate the mass loss of the material and found in conformity with the test result. The matrix material wears severely at the starting of the test up to $2 \mathrm{~km}$ distance and changed linearly with increasing the sliding distance $(6 \mathrm{~km})$ while the wear rate of $\mathrm{Al}_{2} \mathrm{O}_{3}$ particle reinforced AA6061 was linear. Based on the scanning micrograph images, wear detritus and sample surface abrasion and adhesion wear mechanisms were inherent for both base matrix alloy and composite material. In addition, angular-shaped wear detritus removed from the surface of the particle reinforced composite with noncontinuous grooves on its surface was observed. And the reverse was true for the matrix wear test result. Based on this, it was deduced that the incorporation of ceramic particle reinforcements can enhance the wear resistance capacity of metals by avoiding the existence of abrasive wear. And, when the testing pressure was varied, an insignificant wear rate was noticed for the composite till the testing pressure was reached to $0.7 \mathrm{MPa}$ followed by a dramatic increase with increasing pressure bringing a huge wear detritus and crude finish. A conversion from severe wear to sliding wear was observed when the pressure was increased to $9 \mathrm{MPa}$. This was attributed due to the effect of strain hardening and oxidisation of the material at its boundary, resulting in a desirable wear resistance capacity of the composite as compared to the matrix alloy (wear rate was decreased by 
$10 \%)$. Also, this improvement was reported due to the higher capacity of incorporated hard $\mathrm{Al}_{2} \mathrm{O}_{3}$ particles to resist distortion and retard the transition to severe wear and metallic oxides create small-sized wear detritus. Finally, a remarkable wear resistance behaviour of the composite than the matrix was also observed when the sliding speed was varied. However, the increased wear rate of the composite was observed with increasing the sliding speed till $600 \mathrm{rpm}$ followed by a slight drop and a dramatic rise at a speed of $1400 \mathrm{rpm}$. This was ascribed due to the presence of severe wear with increase in the sliding speed. And, the drop in wear rate between 600 and $760 \mathrm{rpm}$ was due to the creation of metal oxides which are able to harden the surface material. A detailed clarification of this can be referred to in the original article [4].

On the other hand, the effect of macro and nanosized reinforcing particles on AMCs was studied by Akbari et al. [28]. The origin of the study was based on even dispersion of reinforcing particles, wettability, clustering and agglomeration, and the extent of reinforcing particles to be engulfed by the liquid matrix on the course of processing. To identify this, A356 alloy as a matrix and $\mathrm{TiB}_{2}$ reinforcing powders with intermediate sizes of $5 \mu \mathrm{m}$ and $20 \mathrm{~nm}$ were used. Kinds of composites with $0,0.5,1.5,3$, and $5 \mathrm{vol} \%$ of micro and nanopowder proportions were prepared by the stir casting method. The composite melt was agitated at a speed of $450 \mathrm{rpm}$ for 8 minutes and cast at various temperatures $\left(750^{\circ} \mathrm{C}, 800^{\circ} \mathrm{C}\right.$, and $\left.900^{\circ} \mathrm{C}\right)$. Before property testing of the composite, cast samples were $\mathrm{T}_{6}$ heat-treated prior to water quenching and artificial ageing. In doing so, the reinforcement incorporation factor of the reinforcing particles was studied and depicted that adding nanopowders from 0.5 to $1.5 \mathrm{vol} \%$ brings an acceptable dispersion of particles with minimal agglomeration and porosity. Also, it is incited that a greater amount of porosity has existed when the casting temperature gets high. This was attributed due to the entrapment of gaseous elements while stirring the composite melt. Final hardness test values reveal that higher hardness of the composite has been recorded when $1.5 \mathrm{vol} \%$ reinforcing nanopowder was incorporated than the micropowder reinforced composite. The reason for this was ascribed due to the presence of moderate dispersion of nano$\mathrm{TiB}_{2}$ particles in the matrix which helps the powders to be engulfed by interior fine dendrites. Similarly, UTS and elongation of the composite were enhanced by $54 \%$ and $30 \%$, respectively, and a fivefold increase in toughness property of the composite was gained when $1.5 \mathrm{vol} \% \mathrm{TiB}_{2}$ nanopowder was incorporated into the base matrix. The reason for these improvements was depicted due to the Orowan strengthening and Hall-Petch mechanism that it has a substantial effect to regulate the tensile property of the nanocomposite. Extra to this, the experimental mechanical property values of the composites were predicted using the Levenberg-Marquardt algorithm neural network to save wastage of time and material and come up with a high degree of precision (an error value of less than 5\%).

The effect of $\mathrm{TiB}_{2}, \mathrm{~B}_{4} \mathrm{C}$, and $\mathrm{ZrSiO}_{4}$ on the mechanical property of A1356.1 base matrix was analysed by varying the composition, processing temperature, and stirring time of the composite melt, heated to $750 \pm 20^{\circ} \mathrm{C}$ and $850 \pm 20^{\circ} \mathrm{C}$ [29]. $\mathrm{TiB}_{2}$ and $\mathrm{B}_{4} \mathrm{C}$ with a particle size of less than $10 \mu \mathrm{m}$ and 99\% purity and $\mathrm{ZrSiO}_{4}$ with a particle size less than $10 \mu \mathrm{m}$ and $97 \%$ purity were used with 5,10 , and $15 \mathrm{vol} \%$ proportions. Reinforcing particles were incorporated into the matrix melt and stirred between 350 and $400 \mathrm{rpm}$ in various stirring times. For uniform dispersion of reinforcing particles in the matrix, additional stirring time was added as the proportion of reinforcing particles increased ( 8 minutes for $10 \mathrm{vol} \%$ and 12 minutes for $15 \mathrm{vol} \%)$. Hardness test results of these were generally higher than those of the base alloy. Nevertheless, the hardness property of $\mathrm{Al}-10 \mathrm{vol} \% \mathrm{TiB}_{2}$ at $850^{\circ} \mathrm{C}$ composite was greater than its alternatives (Al-10vol\% $\mathrm{B}_{4} \mathrm{C}$ and $\mathrm{Al}-10 \mathrm{vol} \% \mathrm{ZrSiO}_{4}$ ). The reason for this change was attributed due to the minimal clustering of $\mathrm{TiB}_{2}$ reinforcing particles with increasing its proportion in the base matrix. Apparent to this, with increasing the processing temperature, a change in hardness value of the composite was depicted which is highly related to the final microstructure of the prepared composites. Settled ceramic reinforcing particles were exhibited around the extent of grain boundaries since it needs additional time to attain solidification. To the reverse, $\mathrm{Al}-10 \mathrm{vol} \% \mathrm{ZrSiO}_{4}$ at $750^{\circ} \mathrm{C}$ composite exhibited an increased amount of UTS property compared to its alternatives $\left(\mathrm{A} 1-10 \mathrm{vol} \% \mathrm{~B}_{4} \mathrm{C}\right.$ at $850^{\circ} \mathrm{C}$ and $\mathrm{Al}-10 \mathrm{vol} \% \mathrm{TiB}_{2}$ at $750^{\circ} \mathrm{C}$ ). And it was generally reported that incorporating reinforcing particles greater than 10 vol\% yields a diminishment in the mechanical property of the composite which may be due to the formation of agglomerates and porous structure. Likewise, the experimental mechanical property of the composites was predicted using Levenberg-Marquardt algorithm neural network to save wastage of time and material and come up with a high degree of precision too.

Preheated high carbon steel machining chips of 5 and $10 \mathrm{wt} \%$ at a temperature of $200^{\circ} \mathrm{C}$ were fabricated with Al6063 matrix using the stir casting method. Al6063 was melted to a temperature of $800^{\circ} \mathrm{C}$ and the composite was stirred at a speed of $300 \mathrm{rpm}$ for 5 minutes which gives better results. Final test results indicate that increasing the percentage of high carbon steel chips from 5 to $10 \mathrm{wt} \%$ increases the mechanical properties UTS $(167 \mathrm{MPa})$ and hardness (186HRC) than the matrix material alone [3]. Moreover, steel particulates were used with other reinforcements ( $\mathrm{SiC}$ and graphite) with $\mathrm{Al}-\mathrm{Mg}$-Si alloy matrix. Preheated reinforcements at a temperature of $250^{\circ} \mathrm{C}$ with 4,6 , and $8 \mathrm{wt} \%$ were used. The composites were manufactured by doublestep stir casting process; first, the alloy was melted to a temperature of $750 \pm 30^{\circ} \mathrm{C}$, cooling to $600^{\circ} \mathrm{C}$, adding reinforcing particulates, and stirring for 5 to 10 minutes followed by superheating to $780 \pm 30^{\circ} \mathrm{C}$ at a stirring speed of $400 \mathrm{rpm}$. Test results show that a higher hardness value of the composite was observed when $8 \mathrm{wt} \%$ of steel particulate was replaced by $8 \mathrm{wt} \%$ of $\mathrm{SiC}$ and other reinforcement combinations such as $7 \mathrm{wt} \%$ steel particulates and $1 \mathrm{wt} \%$ graphene and $6 \mathrm{wt} \%$ steel particulates and $2 \mathrm{wt} \%$ of graphene. But UTS values of the composite were higher when $8 \mathrm{wt} \%$ of steel particulates was used than other reinforcements attributing due to the presence of greater undercooling of steel particles which results in grain refinement. Also, the fracture 
toughness was higher for composites having only steel particulates and hybrid steel and graphite particles than composites having $8 \mathrm{wt} \% \mathrm{SiC}$ reinforcements. The reason was depicted due to the existence of steel particles which are stronger than aluminium but equally ductile. Also, wear behaviour test results indicate that composites containing hybrid reinforcing particles ( $6 \mathrm{wt} \%$ steel particles and $2 \mathrm{wt} \%$ graphite) have high wear resistance capacities. This was due to the solid-state lubricating property of graphite [30]. Moreover, AMCs fabricated by stir casting route can also be referred in research works with the following matrix/reinforcement combinations: $\mathrm{Al}^{16061 / \mathrm{TiB}_{2}}$ [31], A356/10\% $\mathrm{B}_{4} \mathrm{C}$ [32], $\mathrm{Al} 7075 / \mathrm{B}_{4} \mathrm{C}$ [21], $\mathrm{AA} 1070$ and $\mathrm{AA} 6063 / \mathrm{B}_{4} \mathrm{C}$ [33], $\mathrm{Al}-$ $\mathrm{SiC} / \mathrm{B}_{4} \mathrm{C}$ [34], Al-SiC/graphite [35], and Al6061/SiC [36].

In the present times, carbon fibres have given a much intense aspiration to prepare metal matrix composites such as AMCs. This is because carbon fibre is a flexible strengthening material having excellent physical, mechanical, and tribological properties such as prominent aspect ratio, superior thermal conductivities, excellent chemical consistency, high elastic, specific modulus, and specific strength and impact strength as compared to other alternative reinforcing materials utilized to prepare MMCs. It is presented that a reduction in coefficients of thermal expansion of copper and aluminium was gained by incorporating simply $30 \%$ carbon fibre as a reinforcement. In addition, a significant increase in wear resistance and coefficient of friction of copper was achieved by adding short carbon fibre reinforcement. Due to these realities, carbon fibre reinforced MMCs are ideal and significantly applicable engineering materials in electronics, automobile, aircraft, boats, turbine blades, machine parts, and pressure vessel manufacturing industries. However, the poor wettability and kind dispersion, interfacial reaction with the matrix, and alignment of carbon fibre reinforcements inhibit the growth of carbon fibre reinforced AMCs which significantly affect their mechanical properties [37-39].

The effect of chopped carbon fibre reinforcement was used with Al-Si alloy base matrix by using the stir casting technique [38]. The study was aimed to analyse the effect of the shape of the crucible (having square and round geometry) and stirring speed on the distribution of short carbon fibre reinforcements in the base matrix which was held by varying the stirring velocity with $400,600,800$, and $1000 \mathrm{rpm}$. The volume of the matrix melt was kept constant, and graphite crucibles with $75 \mathrm{~mm}$ depth and $48.7 \mathrm{~mm}$ side length and round crucible with a diameter of $55 \mathrm{~mm}$ were used. Chopped polyacrylonitrile-based carbon fibres having a diameter of $8 \mu \mathrm{m}$ were progressively incorporated into the matrix melt heated to $80^{\circ} \mathrm{C}$ followed by quenching of the specimen in water for cooling. It was reported that the shape of the crucible and the rotational speed of the stirrer affect the dispersion of carbon fibre reinforcements and its mechanical property. Related to this, the tensile strength of the composite prepared by square crucible was $48.3 \%$ higher than the composite prepared by its alternative. The reason for this change and improvement was attributed because the uniform dispersion of short carbon reinforcements in the base matrix was exhibited for the square crucible case even if uninfiltrated fibres are present in dead regions. This was because of the generation of secondary flow turbulent streams in addition to the mainstream and the conviction among them while stirring. Also, it was because the high velocity among flow streams has a shearing effect of the composite melt with the wall of the crucible all of which exist due to the nonaxisymmetric arrangement of the square crucible. However, a huge amount of cavity defects due to fibre clustering, poor infiltration, and uneven dispersion of fibre in the matrix was exhibited for the composites prepared by the round crucible. This was ascribed due to the absence of secondary flow streams adequate to generate high turbulence intensity capable of distributing the short fibres in the matrix. Seeming to this, AA7075/short coated carbon fibre $(1,2$, and $3 \mathrm{wt} \%)$ composite was prepared by the stir casting method, and a $41.25 \%$ increase in the composite UTS was achieved as compared to the matrix alloy [40].

2.2. Friction Stir Processing (FSP). FSP is the fast emerging and ideal process to prepare both metallic and ceramic particle reinforced AMCs. FSP is categorized into severe intense plastic deformation technique which has received much research focus in recent times. It is evolved from the recently developed friction stir welding (FSW), which was invented at The Welding Institute (TWI) two decades ago [41]. FSP is a solid-state process wherein the reinforcing particles are combined with the matrix material in a plastic state. It has become standard practice to machine a reservoir in the form of grooves or holes on the surface of the aluminium matrix plate for which the reinforcing particles are to be rammed down with FSP method. Figure 2 shows a schematic illustration of FSP how the reservoir is deposited with reinforcement particles; [42] nonconsumable rotating tool creates adequate frictional heat upon contact with the plate surface to plasticize the matrix. The traverse motion of the tool extrudes the plasticized composite mixture to the back of the tool and is forged due to the application of axial force. The deformed material is transferred from the retreating side (RS) of the tool pin to the advancing side (AS) and is forged by the tool shoulder, resulting in a solid-state modification of the material $[43,44]$. The tool material should be strong enough to create adequate friction and resist wear due to the abrading action of reinforcing particles. During FSP, tool rotational speed, traverse speed, axial force, tool geometry, size of the groove or hole, type of processing tool, and the number of passes are the significant process parameters to be considered for efficient production of the composite material which is discussed next in various experimental works [43].

It is an efficient technique to produce high-quality AMCs in their solid state with minimum energy consumption, good interfacial bonding between the matrix and the reinforcement, fine-grained structure of the composite, and no need for secondary processing of the final composite material. Also, composites produced with this method are free of defects since there is a uniform distribution of the reinforcing particles throughout the matrix plate. This makes AMCs to be free of porosity and agglomeration and to 


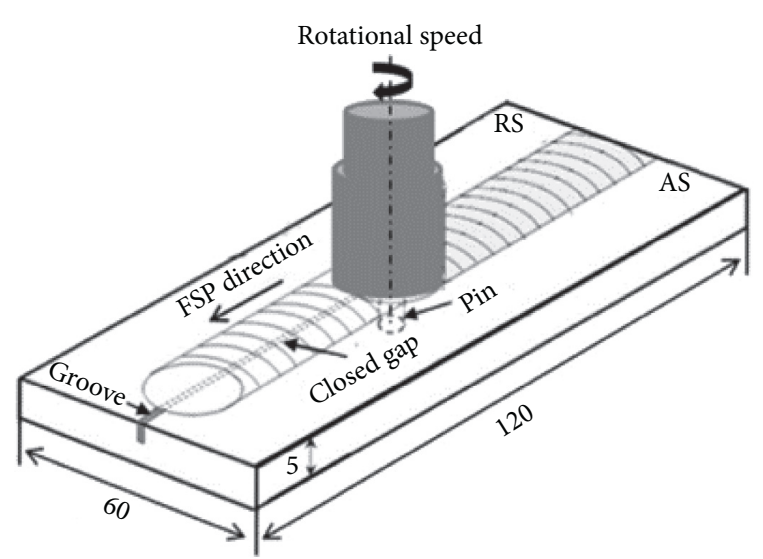

FIgURE 2: Schematic illustration of the process of FSP [42].

have poor interfacial bonding making the composite dense and strong enough to resist load in different conditions. These may be due to the application of high pressure used to consolidate the reinforcement particulates with the base matrix during processing which lessens the formation of porosities as compared to other processing methods.

Related to this, Wang et al. [42] have applied this novel method using rolled $5 \mathrm{~A} 06 \mathrm{Al}$ plate as a matrix and $\mathrm{SiC}$ particle, size of about $10 \mu \mathrm{m}$ as a reinforcement. A plate having a respective width and depth of a groove of 0.5 and $1 \mathrm{~mm}$ has been used. A high-speed steel tool having a rotational speed of $1180 \mathrm{rpm}$ and a travel speed of $95 \mathrm{~mm} / \mathrm{min}$ was used for processing of the composite. And a $10 \%$ increase in the microhardness of the composite was observed than the base matrix that it was attained due to the inherent distribution of $\mathrm{SiC}$ particles on the surface of the matrix. In addition, Puviyarasan and Praveen [45] have manufactured AMC by using AA6063- $\mathrm{T}_{6}$ rolled plate and bulk $\mathrm{SiC}$ with a particle size of $3 \mu \mathrm{m}$ using the FSP route. While processing, process parameters such as high-speed steel at $1000 \mathrm{rpm}$, traverse speeds of 30,40 , and $50 \mathrm{~mm} / \mathrm{min}$, and groove sizes of $1.2,1.5$, and $1.8 \mathrm{~mm}$ with $6 \mathrm{~mm}$ depth were used. The final hardness test results of the composite show that a $30 \%$ increase in hardness was gained at a smaller traverse speed. This was because the shoulder provides sufficient force and heat during processing.

Aluminium alloy AA6082 matrix and $\mathrm{TiC}$ with a particle size of $2 \mu \mathrm{m}$ have been used to make the composite using FSP technique by Thangarasu et al. [46]. A groove having a depth of $5 \mathrm{~mm}$, widths of $0,0.4,0.8,1.2$, and $1.6 \mathrm{~mm}$, and respective process parameters such as tool rotational speed, traverse speed, and axial force of $1200 \mathrm{rpm}, 60 \mathrm{~mm} / \mathrm{min}$, and $10 \mathrm{KN}$ was used in making the composite. The volume fraction of $\mathrm{TiC}$ was varied as $0,6,12,18$, and $24 \mathrm{vol} \%$. Final microhardness and tensile strength property test results of the composite showed that a significant increase in microhardness and tensile strength property was gained when $24 \mathrm{vol} \%$ of TiC particle reinforcements was incorporated. The reason for these was attributed due to the uniform distribution of reinforcing particles which are capable of impeding the movement of dislocations and reduced formation of voids while increasing the vol\% of TiC particles. Likewise,
Selvakumar et al. [8] have used stainless steel particulate reinforcement with a size of approximately $40 \mu \mathrm{m}$ with AA6082 matrix. Almost similar process parameters were applied to make the composite with the FSP technique. Results of tensile strength and ductility tests were higher than the matrix alone, and here, the tensile test result value was lower than the previous investigation that it may be due to the incorporated volume fraction of the reinforcement, only limited to $18 \mathrm{vol} \%$. Moreover, the ductility of the composite was improved accordingly since stainless steel particles are highly ductile as compared to the commonly used ceramic reinforcement particles.

The influence of process parameters on the mechanical properties of Al5052 was determined using $\mathrm{SiC}$ reinforcement particles with sizes of $5 \mu \mathrm{m}$ and $50 \mathrm{~nm}$ [47]. Combinations of traverse speeds $(40,80$, and $125 \mathrm{~mm} / \mathrm{min})$ and rotational speed $(700,1120$, and $1400 \mathrm{rpm})$ were used. Final test results show that a 55\% increase in hardness has been observed due to the incorporation of $\mathrm{SiC}$ particles. This increase has attained while the size of reinforcing particles was decreased to the nanolevel, changing the direction of tool rotation among passes and more amount of FSP counts. Similar to this, in the work of Jeon [48], Al5052-H32 matrix was reinforced with graphene having sizes of $1 \mathrm{~nm}$ and $1-3 \mu \mathrm{m}$ reinforcements. Graphene has been used because of its excellent mechanical property keeping the lighter aluminium matrix. Tool rotational speeds of $700 \mathrm{rpm}$ and traverse speed of $70 \mathrm{~mm} / \mathrm{min}$ were used as process parameters. Test results depict that the composite does not show any noticeable macroscopic imperfections. And quasistatic tensile test results show that a significant increase in ductility and a slight decrease in tensile strength of both the alloy and composite were observed. The increase in the ductility was due to the existence of dynamic recrystallization while processing.

Rolled AA6061 alloy in annealed condition was reinforced with hybrid $\mathrm{Al}_{2} \mathrm{O}_{3}$, the particle size of $320 \mathrm{~nm}$ with $10.3 \mathrm{wt} \%$, and multiwalled CNTs (diameter ranging from $10 \mathrm{~nm}$ to $20 \mathrm{~nm}$ and length ranging from 10 to $30 \mu \mathrm{m}$ ) with $0.5 \mathrm{wt} \%$ concentration [49]. FSP parameters such as tool rotational speed of $1200 \mathrm{rpm}$, traverse speed of $3 \mathrm{~mm} / \mathrm{sec}$, and tool tilt angle of $3^{\circ}$ were used. Mechanical test result values indicate that a substantial increase in hardness, yield, and UTS properties of the composite has been observed than the AA6061 base matrix due to the addition of hybrid $\mathrm{Al}_{2} \mathrm{O}_{3}$ CNTs reinforcements. The reason for these improvements was depicted due to the Orowan strengthening mechanism. However, a significant decrease in elongation of the composite was observed since high energy is needed for the yielding of the composite to take place. Also, the investigation of Dinaharan et al. [50] showed that using AA6061 alloy and $18 \mathrm{vol} \%$ RHA, the approximate size of $8 \mu \mathrm{m}$ reinforcement was done by applying the FSP method. 100, 1.2, and $5.5 \mathrm{~mm}$ were the length, width, and depth of the grooves, respectively. Process parameters such as tool rotational speed of $1600 \mathrm{rpm}$, traverse speed of $60 \mathrm{~mm} / \mathrm{min}$, and axial force of $10 \mathrm{KN}$ per pass were used during FSP. After doing so, a substantial increase in the UTS of the composite was gained due to the addition of RHA particles. The cause for 
this was attributed due to the fine structural changes by FSP and the addition of RHA particles. Identical to this, AA6061 alloy was reinforced by $18 \mathrm{vol} \%$ FA particles with an approximate size of $5 \mu \mathrm{m}$ by applying similar process parameters [51]. Microindentation test results reveal that the addition of FA particles brings a significant increase in the hardness value of the composite. The reason was attributed due to the uniform dispersion of reinforcing particles throughout the base matrix and helping to hinder the movement of dislocation.

Tungsten with a particle size of $1-5 \mu \mathrm{m}$ and $99.9 \%$ purity was incorporated into the 1060-H14 aluminium alloy [44]. Process parameters such as the rotational speed of $1200 \mathrm{rpm}$ and tool traverse speed of $40 \mathrm{~mm} / \mathrm{min}$ were applied and found to bring a friction stir processed surface free of defects. Mechanical property tests such as tensile strength and microhardness of the processed composite were improved to a significant level which was processed with five passes.

Moreover, the mechanical property of rolled and $\mathrm{T}_{6}$ treated AA7075 alloy was studied by incorporating various filler materials independently [52]. To do this, filler reinforcements (SiC, with a grain size of $25 \mu \mathrm{m}, \mathrm{Cu}$, with a particle size of 10-20 $\mu \mathrm{m}$, and MWCNTs having a respective mean length and diameter of $5 \mu \mathrm{m}$ and $15-20 \mu \mathrm{m}$ ) were incorporated into the base matrix (cylindrical holes with 3 and $2 \mathrm{~mm}$ depth and diameter, respectively). Filler particles were used $5.3 \mathrm{vol} \%$ and consolidated into the reservoirs at a speed of $800 \mathrm{rpm}$ and a traverse speed of $60 \mathrm{~mm} / \mathrm{min}$ with the novel FSP technique. After processing, artificial ageing was applied, followed by cooling to normal temperature in air. Hardness test results of this reveal that $\mathrm{SiC}$ particle incorporated AA7075 base matrix shows a twice increase in hardness property than $\mathrm{Cu}$ (intermediate hardness value) and MWCNT (lower hardness value) reinforced composites. The reason for these improvements was ascribed due to the more eminent hardness characteristics of the particular fillers and the Orowan strengthening mechanism. The remarkable increase in hardness of the $\mathrm{SiC}$ particle reinforced composite was further attributed due to grain disintegration, local distortion, allied distribution hardening, and hindrance of the movement of $\mathrm{SiC}$ particles around the grain boundaries created while processing. It was also stated due to the formation of uniformly distributed $\mathrm{MgZn}_{2}$ precipitates and the existence of uniform nucleation sites because of extended ageing time and lower ageing temperature. Similarly, a twice improvement in the impact property of $\mathrm{SiC}$ particle reinforced composite was depicted than the base matrix. And an increase in impact toughness of the composites after ageing was depicted for all cases. This was reported due to the removal of crack generation acted by the resistance of $\mathrm{MgZn}_{2}$ precipitates and distributed reinforcing particles in the base matrix.

2.3. Solid-State Powder Metallurgy Followed by Secondary Manufacturing Processes. Figure 3 shows the schematic illustration of the powder metallurgy processing method to produce MMCs [53]. It is a technique in which fine powders of the matrix (aluminium and its alloys) and reinforcing particles are blended and bonded in their solid state by compacting at room temperature or slightly above making the composite to its desired size and shape followed by solidstate sintering, meaning that the compacted material will be heated in a controlled atmosphere below its recrystallization temperature which helps to reduce the amount of porosity and foreign matters imparted during compaction processes. And after this, the composite will be deformed, extruded, or forged above room temperature to enhance the mechanical property of the composite by reducing porosity and increasing the bond between the matrix and reinforcing particles. Powder metallurgy can produce exactly net-shaped components of complex attribute with high accuracy [19]. And it is very important to know that all particles are homogeneously distributed in the mixture which helps to obtain a composite having good microstructure and mechanical properties in using this processing route [20].

To clarify this, in the work of Esawi et al. [54], a pure aluminium matrix was reinforced with a $2 \mathrm{wt} \%$ multiwall carbon nanotube (MWCNT). Powders were blended and mixed with a planetary ball mill at $200 \mathrm{rpm}$ for 3 and 6 hours. Ball-milled powders were compacted at $475 \mathrm{MPa}$ load in a compaction die, and finally, the green compact was hotextruded at a temperature of $500^{\circ} \mathrm{C}$. Vickers microhardness and nanoindentation test results confirm that MWCNT reinforced aluminium composites show both higher microand nanoindentation tests as compared to the nonmilled pure aluminium matrix. But lower micro and nanoindentation hardness values than the 6-hour milled aluminium base matrix were recorded. In addition, tensile strength tests show that 3 -hour milled and $500^{\circ} \mathrm{C}$ annealed MWCNT incorporated composite was improved significantly. Uniform dispersion of MWCNT in the aluminium matrix was the reason for this increase. Identically, the influence of ball milling time in pure aluminium/MWCNT composite and its mechanical property was analysed by Liu et al. [55]. Powders were milled at a speed of $300 \mathrm{rpm}$ by changing the milling time with $2,4,6,8$, and 12 -hour milled powders were then cold compacted in a die and hot-pressed at a temperature of $560^{\circ} \mathrm{C}$ to billets after degassing. The preformed billets were then hot-forged to their final shape at a temperature of $450^{\circ} \mathrm{C}$. A respective increase by $42.3 \%$ and $18.4 \%$ of yield strength and UTS of the composite has been observed when the ball milling time of the powders was increased to 6 hours. And a further increase in ball milling time has decreased these properties with negligible elongation of the composite. These decreases in the property were attributed due to the damaging of MWCNT, and imparting of impurities exists with increasing the ball milling time.

Mechanical properties of Al2024/MWCNT composite were manufactured and analysed by Jafari et al. [56]. 0 to $3 \mathrm{vol} \%$ MWCNT of $95 \%$ purity were incorporated in Al2024 and ball-milled for 1 and 4 hours at a speed of $350 \mathrm{rpm}$ in an inert atmosphere. Powders of the milled nanocomposite were hot-compacted in a uniaxial die at a load of $250 \mathrm{MPa}$ and cooled in air. Hardness test results show that a $15.5 \%$ increase in the hardness of the nanocomposite was observed when 2 vol\% of MWCNT was incorporated. Also, a 


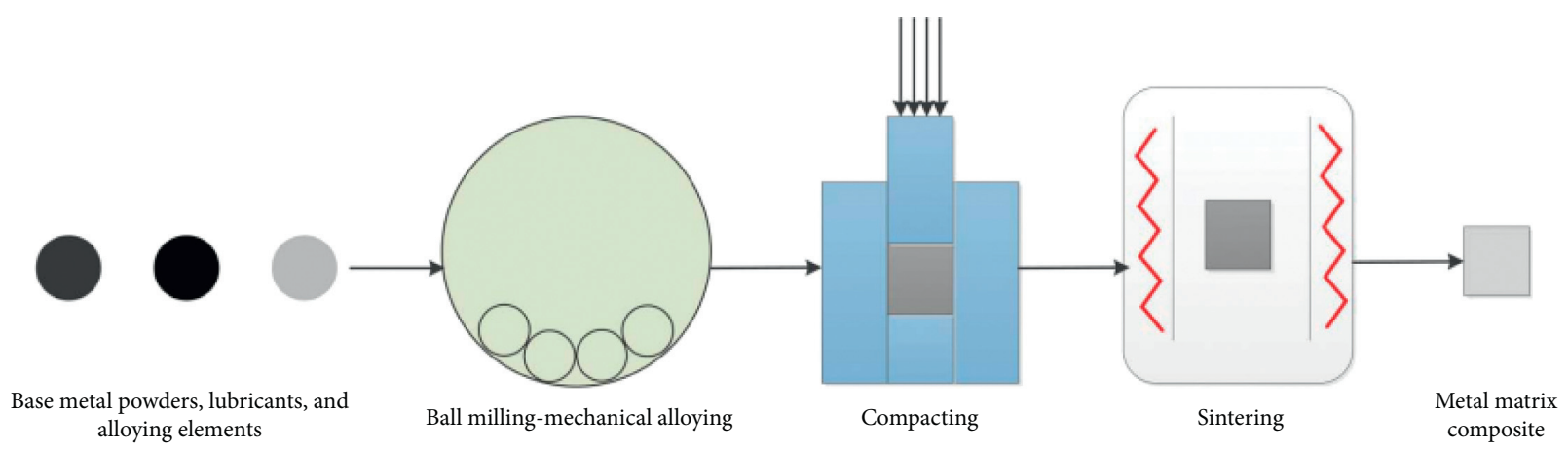

Figure 3: A Schematic illustration of the powder metallurgy technique to prepare MMCs [53].

respective increase in 10 and $12 \%$ of yield and ultimate compressive strength of the nanostructured Al2024/ MWCNT composite was gained when a $2 \mathrm{wt} \%$ of MWCNT was incorporated. It was also higher than the Al2024- $\mathrm{T}_{6^{-}}$ treated alloy. The improvement in the mechanical properties of this nanostructured composite for $2 \mathrm{vol} \%$ was attributed due to the dispersion strengthening and restraining grain growth of aluminium during hot processing. Besides, Al2024 alloy powder was reinforced by $\mathrm{B}_{4} \mathrm{C}$ powder reinforcement $[57,58]$. Al2024/20wt $\% \mathrm{~B}_{4} \mathrm{C}$ powders were blended and milled at a speed of $510 \mathrm{rpm}$ for 24 hours in an argon atmosphere [57]. Composite powders were compacted in a vacuum atmosphere at a sintering temperature of $550^{\circ} \mathrm{C}$ followed by hot extrusion of consolidated billets at this temperature. For comparison, another composite with coarse-grained Al2024 and Al2024/ $\mathrm{B}_{4} \mathrm{C}$ powders were blended and prepared with similar processing parameters. Uniform distribution of $\mathrm{B}_{4} \mathrm{C}$ particles due to sintering and hot extrusion resulting in no noticeable pores and densification of the composite was observed. Due to this and other factors, a twice increase in hardness and compression strength of the $\mathrm{Al} 2024 / \mathrm{B}_{4} \mathrm{C}$ composite was observed. Moreover, adding 10wt $\%$ coarse Al2024 powder to the composite shows a beneficial strength and ductility combinations. A detailed clarification of this can be referred to [57]. Also, $\mathrm{Al} 2024 / 5 \mathrm{wt} \% \mathrm{~B}_{4} \mathrm{C}$ composite powder was prepared by attrition milling at a speed of $400 \mathrm{rpm}$ [58]. The final shaping of the composite was done using hot extrusion at a temperature of $750^{\circ} \mathrm{C}$ after hot compacting of the powders. Mechanical property test results show the highest hardness, tensile, yield, and UTS than the coarse-grained Al2024 and the milled Al2024 alloy. Orowan strengthening and Hall-Petch mechanisms are attributed for the change and improvement of the mechanical property of the composite which has existed while extrusion of the composite samples. Extra to these, $\mathrm{B}_{4} \mathrm{C}$ nanoparticles were used as a reinforcement with Al5083 alloy [59]. Powders were mixed and cryomilled for 12 hours using liquid nitrogen at a speed of $180 \mathrm{rpm}$. And, vacuum degassing of the cryomilled powders was applied for about 16 hours. The final composite containing $66.5 \mathrm{vol}$ $\%$ ultrafine-grained Al5083, 30vol\% Al5083 coarse-grained, and $3.5 \mathrm{vol} \%$ nano- $\mathrm{B}_{4} \mathrm{C}$ particles was compacted using hot isostatic pressing at a temperature of $400^{\circ} \mathrm{C}$ and then extruded at this temperature. Results depict that clustering of nanoparticles on grain boundaries of the composite was not observed. Higher compressive and tensile strength property of the composite was observed for the $5 \mathrm{vol} \%$ nano- $\mathrm{B}_{4} \mathrm{C} / \mathrm{Al} 5083$ composite composition as compared to others.

Aluminium flakes were reinforced with $0.3 \mathrm{wt} \%$ graphene nanosheets [60]. First, the graphene oxide/aluminium composite powder was heated to $550^{\circ} \mathrm{C}$ for 2 hours in an argon atmosphere. Then, graphene nanosheets/aluminium composite were compacted and fused into billets, sintered at a temperature of $580^{\circ} \mathrm{C}$, and then hot-extruded at a temperature of $440^{\circ} \mathrm{C}$. The final tensile strength test of the composite has shown a $62 \%$ increase in tensile strength due to the addition of graphene nanosheets. Recently, Kumar and Rajadurai [61] have analysed the influence of $\mathrm{TiO}_{2}$ on $\mathrm{Al}-15 \% \mathrm{SiC}$ base matrix. $\mathrm{TiO}_{2}$ was added with $0,4,8$, and $12 \mathrm{wt} \%$ proportions. Powders were blended uniformly and were preheated to $200^{\circ} \mathrm{C}$ followed by cold compaction of the composite powder at $800 \mathrm{MPa}$. And the green compact was sintered at a temperature of $650^{\circ} \mathrm{C}$ for 2 hours and the furnace was cooled for 8 hours. To this end, final density and microhardness test results of the composite showed a continuous improvement with increasing the composition of $\mathrm{TiO}_{2}$. And this was assumed due to the rise in the dislocation density of the hybrid composite. Also, Narayan and Rajeshkannan [62] have studied the effect of hot forging on the mechanical property behaviour of AMCs. Powder particles of aluminium were reinforced with carbide particles such as $\mathrm{Al}_{4} \mathrm{TiC}, \mathrm{Al}_{4} \mathrm{Fe}_{3} \mathrm{C}, \mathrm{Al}_{4} \mathrm{Mo}_{2} \mathrm{C}$, and $\mathrm{Al}_{4} \mathrm{WC}$. These composite powders were blended and mixed using a ball milling rotating at a speed of $200 \mathrm{rpm}$ for 2.5 hours. Compacts were then prepared by using a hydraulic press and dried at a temperature of $200^{\circ} \mathrm{C}$ followed by sintering of the compacts at a temperature of $594^{\circ} \mathrm{C}$ for an hour and forged to their final shapes. In their work, kinds of cooling/heat treatment processes were applied to enhance the mechanical property and were compared with added reinforcement particles. Final test results showed that a $12 \%$ increase in UTS of pure aluminium preforms cooled with water and a $15 \%$ increase in UTS of the aluminium matrix composite reinforced with $\mathrm{TiC}$ and $\mathrm{WC}$ were attained. Aluminium reinforced with $\mathrm{WC}$ has shown the biggest hardness property even if the variation was not significant and poor hardness values were recorded for all cooled pure aluminium samples. In addition, the impact resistance capacity of 
the cooled pure aluminium and the carbide reinforced composites were all lower than the virgin aluminium preforms. Moreover, Sethi et al. [9] have manufactured AMCs using $30 w t \% \mathrm{Y}_{2} \mathrm{~W}_{3} \mathrm{O}_{12}$ with $0,5,10$, and $15 w t \%$ of AlN and $30 w t \%$ AlN with $0,5,10$, and $15 w t \% \mathrm{Y}_{2} \mathrm{~W}_{3} \mathrm{O}_{12}$ compositions. The composite powders were ball-milled for 10 hours at a speed of $300 \mathrm{rpm}$. The milled powders were then subjected to compaction under $600 \mathrm{MPa}$ load followed by sintering at $600^{\circ} \mathrm{C}$ for 1 hour and subsequent forging at $400^{\circ} \mathrm{C}$ to its final geometry. And it is reported that the relative density of all the forged composites was higher than that of the sintered composites. This may be due to the reduced amount of porosity by faster diffusion of metal under high compressive pressure during hot forging. An increase in hardness values of the hybrid composites was observed and the reasons for this are more elaborated in [9]. Moreover, the theoretical and experimental values of the composite were compared and experimental values were lower than the theoretical value that it was attributed due to the presence of porosities in the hybrid composites. Also, high compressive strength values were gained by increasing the amount of $\mathrm{AlN}$ in $\mathrm{Y}_{2} \mathrm{~W}_{3} \mathrm{O}_{12}$-rich composite. It has been enhanced by approximately 29,37 , and $43 \%$ when 5, 10, and $15 \mathrm{wt} \%$ AlN are added, respectively. However, the reverse is not true that an approximate decrease in compression strength of the composite by 13,16 , and $19 \%$ was recorded when respective compositions 5, 10, and $15 \mathrm{wt} \%$ of $\mathrm{Y}_{2} \mathrm{~W}_{3} \mathrm{O}_{12}$ were added. This decrease was attributed due to the minimal strength of $\mathrm{Y}_{2} \mathrm{~W}_{3} \mathrm{O}_{12}$ in comparison with AlN. Furthermore, related research works on aluminium matrix reinforced by carbon nanotubes and processed by wet mixing combined with powder processing route [63] and $12 \mathrm{wt} \% \mathrm{~B}_{4} \mathrm{Cl}$ $6061 \mathrm{Al}$ reinforced by nano- $\mathrm{Al}_{2} \mathrm{O}_{3}$ particle [64] were manufactured by powder metallurgy route, and a significant increase in the tensile strength of the composites was gained.

2.4. Spark Plasma Sintering (SPS) Process. SPS is an alteration of hot pressing which uses low voltage and low-intensity pulsed current under a uniaxial pressure for sintering of materials such as metal matrix composites. It is an effective technique to manufacture metal matrix composites that it is capable of gaining a fully densified composite by incorporating hard and strong ceramic particulate reinforcements in a quick sintering time [65]. The process is done with a minimal sintering temperature ranges which help to limit grain growth, making small grain-sized laminated MMCs having improved mechanical properties of which their strength depends on the bond strength among layers [66]. Figure 4 illustrates the SPS process capable of making MMCs. The process is carried out by first putting the powder composite mix in a die. Pulsed direct current is allowed to pass through the die and the composite simultaneously by a constant uniaxial pressure through the hydraulic pistoncylinder mechanism acting as an electrode too. In doing so, the process is done in an evacuated system/low vacuum condition to avoid oxidation and lower thermal conduction of the die and the composite. After finishing the sintering process, heating will be switched off, removing the pressure and allowing to chill in the atmosphere [65].
Related to this fact, SPS is a novel and ideal technique to produce MMCs which are sensitive for oxidation, explosion, and easily reactive characteristics with the surrounding while processing aluminium, magnesium, and titanium matrix composites. These and other traits of MMCs are possibly controlled by this method of manufacturing since the process is carried out by quickly heating with a spark plasma under a vacuum atmosphere [66-68]. Moreover, it is advantageous over other alternative processing methods such as stir casting and powder metallurgy that it is possible to get a composite of which reinforcing ceramic particles are dispersed uniformly with fine microstructure [69].

Associated with this, Al2024 powder having a particle size of $45-105 \mu \mathrm{m}$ was used as a matrix and reinforced with CoFeMnNi high-entropy alloy powder with a particle size of lower than $50 \mu \mathrm{m}$ with $70 \mathrm{vol} \%$ composition [70]. To avoid agglomeration, reinforcing powder was incorporated into the matrix and mixed uniformly with the help of a lowenergy ball milling machine in a vacuum atmosphere. It was then united and strengthened by using the SPS technique at a temperature of $549.85^{\circ} \mathrm{C}$ and $40 \mathrm{MPa}$ load in a controlled atmosphere. The results of this show that the Vickers hardness of the composite was enhanced by $63.7 \%$ as compared to the hardness value of the base matrix. The reason for this was inferred due to the formation of the interdiffusion layers which was capable of reducing defects related to sintering. This improvement was further attributed due to the uniform dispersion of atoms on the diffusion layer during processing, and the motion of dislocation was hindered by the rendered phases such as $\mathrm{AlCu}_{2}$ and $\mathrm{MnAl}_{6}$ phases and interfaces all of which enhance the deformation resistance behaviour of the composite. Identically, $\mathrm{Al}$ powder with a particle size of $75 \mu \mathrm{m}$ was reinforced by 20,50 , and $80 \mathrm{vol} \%$ SUS316L powder having a particle size of $60 \mu \mathrm{m}$ [71]. Matrix and reinforcing powders were mixed at $200 \mathrm{rpm}$ in a ball milling machine for 12 hours followed by SPS processing done at a sintering temperature of $600^{\circ} \mathrm{C}$, pressure of $200 \mathrm{MPa}$, and time of 5 minutes, respectively. And the Vickers hardness test results of this show that improved hardness of the composite was gained than the matrix and a significant change was exhibited for Al/50vol\% SUS316L proportion. The reason for improvements was ascribed due to the formation of intermetallics; $\mathrm{AlFe}_{4}$ and $\mathrm{AlFe}_{3}$ which have a huge effect on the strengthening of the composite while processing.

AA682 was reinforced by $40 \mathrm{vol} \%$ nano-quasicrystalline $\mathrm{Al}-\mathrm{Cu}-\mathrm{Fe}$ reinforcement by SPS technique [69]. To make the composite, matrix and reinforcing particles have been synthesised separately followed by blending and milling by a high-energy ball milling machine. The milling process was accomplished for 50 hours at a speed of $200 \mathrm{rpm}$. The milled nanocomposite powder was then consolidated at a pressure of $50 \mathrm{MPa}$ and temperatures of 450 and $550^{\circ} \mathrm{C}$ by holding for 5 minutes. Results of this show that uniform distribution of quasicrystalline reinforcing particles in the matrix was observed with a road like and stretched structure later on consolidation for both temperature cases. An increase in both UTS and compressive yield strength of the composite was depicted. This increase was inferred due to 


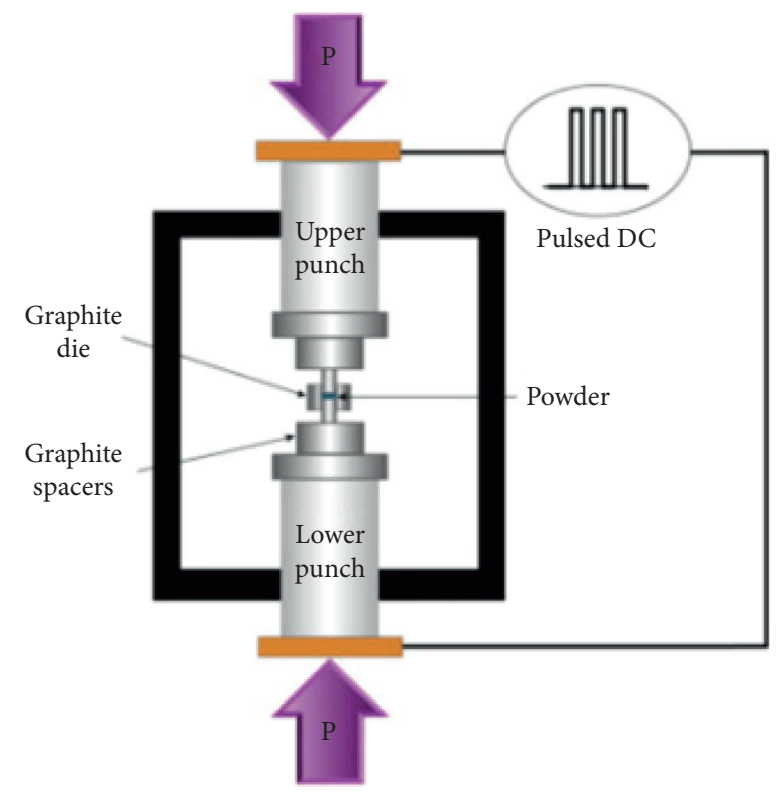

FIgURE 4: Schematic of a typical SPS processing system [65].

microstructural refinement and the existence of intermetallic phases and structural transformation of reinforcing particles inside the nanocomposite powder.

The effect of different reinforcing materials (fine and coarse-grain $\mathrm{SiC}$ and $\mathrm{AlN}$ and only fine-grain $\mathrm{Si}_{3} \mathrm{~N}_{4}$ and $\mathrm{BN}$ with 2, 5, and 10vol\% proportions) was studied on aluminium powder by utilising the SPS route [72]. Also, the effect of sintering temperature on the mechanical property of the composites was under consideration in addition to the particle size and proportion. Before utilising the SPS process for consolidating the composite powders, mixing and homogenization of the $\mathrm{Al} /$ ceramic reinforcing particles were done by using Turbula model mixer. And the consolidation process was done by varying the sintering temperature with 450,500 , and $550^{\circ} \mathrm{C}$ at a pressure of $50 \mathrm{MPa}$ holding for 3 minutes in a vacuum atmosphere. Finally, test results generally depict that particle composition, proportion, grain size, and sintering temperature affect the bulk hardness of the ultimate composite. Associated with this, a comparable increase in hardness was exhibited for fine-grain incorporated $\mathrm{SiC}$ and $\mathrm{AlN}$ and $\mathrm{Si}_{3} \mathrm{~N}_{4}$ (fine-grain) and it was decreased significantly for the case of $\mathrm{BN}$ (fine-grain) reinforced composite. For fine-grain $\mathrm{SiC}, \mathrm{AlN}$, and $\mathrm{Si}_{3} \mathrm{~N}_{4}$ added composites, the increase in hardness of the composite was observed with increasing sintering temperature from 450 to $550^{\circ} \mathrm{C}$ and volume proportion. But the reverse is not true for $\mathrm{BN}$ case. The reason for improvements was deduced due to the densification of the composite with increasing reinforcements with no microstructural coarsening. And, based on the effect of particle size perspective, the superior hardness property of the coarse-grain $\mathrm{SiC}$ incorporated composite was gained at $450^{\circ} \mathrm{C}$ sintering temperature than the fine-grain incorporated composite even though it was not valid with increasing the sintering temperature to $550^{\circ} \mathrm{C}$. Almost similar hardness values of the composite were gained for both coarse and fine-grain AlN particulate filler reinforcements that it was lower than the $\mathrm{SiC}$ incorporated composite. Apart from this, it was reported that the threepoint bending strength and elongation of both 10vol\% coarse-grain $\mathrm{SiC}$ and $\mathrm{AlN}$ particulate reinforced composites increase linearly with increasing sintering temperature. The increase was attributed due to the fact that minimal agglomeration and porosity of the reinforcing particles get fully densified during sintering. And a detailed clarification of this can be referred to in the original document.

Hybrid AMCs were prepared by using the SPS processing method, and the mechanical properties were analysed. Pertinent to this, aluminium powder having a mean size of $75 \mu \mathrm{m}$ was reinforced with hybrid $\mathrm{TiC}$ and $\mathrm{TiB}_{2}$ particle reinforcements in various proportions such as $10 \mathrm{vol} \%\left(3.5 \mathrm{TiC} / 6.5 \mathrm{TiB}_{2}\right)$, $20 \mathrm{vol} \%\left(7 \mathrm{TiC} / 13 \mathrm{TiB}_{2}\right)$, 30vol\% (10.5TiC/19.5 $\left.\mathrm{TiB}_{2}\right)$, and $40 \mathrm{vol} \%$ $\left(14 \mathrm{TiC} / 26 \mathrm{TiB}_{2}\right)[73]$. Composite powders were consolidated by SPS route at pressure, temperature, and time, respectively, of $50 \mathrm{MPa}, 456^{\circ} \mathrm{C}$, and 10 minutes. Up to $10 \mathrm{vol} \%$, uniform dispersion of reinforcing particles in the base matrix was exhibited and the formation of agglomerates and porosity was depicted with increasing the content to $40 \mathrm{vol} \%$. The improved and optimum mechanical property of the composite was achieved when $20 \mathrm{vol} \%$ of hybrid reinforcing particle added to the base matrix. And it was reported that 135, 145, 195, and 194\% increase in hardness, stiffness, yield strength, and UTS were gained, respectively. Formation of hard intermetallic phases at the interphases, hindering the motion of dislocation, and uniform dispersion of hybrid reinforcing particles are all attributed for these improvements. Also, aluminium powder with a size of $1-3 \mu \mathrm{m}$ was reinforced with hybrid $\mathrm{Al}_{2} \mathrm{O}_{3}$ (particle size of $0.5 \mu \mathrm{m}$ ), $\mathrm{SiC}$ (particle size of $0.4 \mu \mathrm{m}$ ), and $\mathrm{Si}_{3} \mathrm{~N}_{4}$ (particle size of $0.5 \mu \mathrm{m}$ ). Multilayer graphene nanosheets having $13.7 \mathrm{~nm}$ mean crystalline thickness was also incorporated for comparison [68]. Aluminium base matrix was reinforced in different proportions and reinforcing phases: $\mathrm{Al} /$ $30 \mathrm{wt} \% \mathrm{Al}_{2} \mathrm{O}_{3}, \mathrm{Al} / 15 \mathrm{tw} \% \mathrm{Al}_{2} \mathrm{O}_{3}+35 \mathrm{wt} \% \mathrm{SiC}$, and $\mathrm{Al} / 50 \mathrm{wt} \%$ $\mathrm{Al}_{2} \mathrm{O}_{3}+10 \mathrm{wt} \% \mathrm{SiC}+5 \mathrm{wt} \% \quad \mathrm{Si}_{3} \mathrm{~N}_{4}+5 \mathrm{wt} \%$ graphene. It was made into disks by homogenising the powders in an attritor mill followed by the SPS method. The SPS process was done by compressing at a pressure of $50 \mathrm{MPa}$ and sintering temperature of $600^{\circ} \mathrm{C}$ in a controlled atmosphere. Test results show that there was a rise in the porosity of the composite with increasing the proportion of ceramic reinforcing particles. This was ascribed due to the difficulty in compacting the hard ceramic particles in the base matrix that it was worse for the graphene nanosheet case. Based on this, a higher hardness value of the composite was gained for $\mathrm{Al} / 30 \mathrm{wt} \% \mathrm{Al}_{2} \mathrm{O}_{3}$ than other compositions. Also, poor wettability and interphase binding and the presence of intermetallics on grain boundaries are deduced for lowering of the composite hardness with increasing the balance of reinforcements. Moreover, aluminium powder with a particle size of $5 \mu \mathrm{m}$ was strengthened by incorporating hybrid MWCNTs (20 nm diameter and 15-50 $\mu \mathrm{m}$ long) and $\mathrm{SiC}$ with a particle size of $25 \mu \mathrm{m}$ reinforcements [74]. MWCNTs with 1, 3, 5wt\%, and $10 w t \% \mathrm{SiC}$ particles were incorporated and mixed in a high-energy ball milling machine at a speed of $250 \mathrm{rpm}$ with aluminium powder. Mixed powders were then preheated to $200^{\circ} \mathrm{C}$ to avoid moisture and taken to the SPS process done at several sintering temperatures for 5 
minutes. Homogeneous distribution of MWCNTs and $\mathrm{SiC}$ particles was exhibited in the matrix, and the formation of MWCNT agglomerates was observed with an increase in its proportion. And, in Al/MWCNTs-SiC hybrid composite, $\mathrm{SiC}$ particles were uniformly dispersed along with MWCNTs in the matrix. This was attributed because grain growth was limited by the applied pressure and generated heat during SPS processing. As a result, a respective increase in microhardness value by $148 \%, 160 \%$, and $172 \%$ was achieved for $\mathrm{Al} / 1 \mathrm{wt} \%$ MWCNTs-SiC, $\mathrm{Al} / 3 \mathrm{wt} \%$ MWCNTs-SiC, and $\mathrm{Al} / 5 \mathrm{wt} \%$ MWCNTs-SiC hybrid composites. This improvement was because the hybrid reinforcements are capable of strengthening effects.

2.5. Squeeze Casting. Squeeze casting process is a special casting technique which has the combined advantages of high pressure die casting, gravity permanent mould casting, and common forging technology. Squeeze casting is also known as liquid metal forging, a combination of casting and forging processes. A slurry of molten matrix and reinforcement will be poured into the bottom half of the preheated die. Then, the pressure will be applied as the metal starts solidifying; the upper half punch closes the die and applies pressure and presses during the solidification process. The required pressure used to produce the composite is considerably lower than that used in forging to manufacture parts of great detail. Squeeze casting operation includes preheating of mould, melting the matrix, pouring it into the mould, and applying pressure and ejection. Figure 5 describes the sequence of operations to be done while preparing a composite with the squeeze casting process [75].

Using squeeze casting than other alternative methods like stir casting and powder metallurgy is advantageous in that there is an elimination of porosity and shrinkage, and better wettability between the matrix and reinforcement, improved mechanical properties, and nearly net shape parts could be achieved.

The effects of $\mathrm{Y}_{2} \mathrm{O}_{3}$-coated $\mathrm{Al}_{2} \mathrm{O}_{3}$ reinforcing particles on Al6061 alloy were analysed after manufactured by squeeze casting technique. Mechanical property test results depict that a huge increase in yield and UTS and elongation of the composite were recorded (respectively, 33.1\%, 27.2\%, and $12.2 \%)$. These improvements were attributed due to the increase in interfacial bonding behaviour created between coated $\mathrm{Al}_{2} \mathrm{O}_{3}$ reinforcing particles and Al6061 alloy [76]. Plus, Singh et al. [77] have fabricated Al6061 matrix reinforced with $\mathrm{SiC}$ particles $(10,15$, and $20 \mathrm{vol} \%$ ) by squeeze casting route. Composite melt was poured into the preheated die and squeezed at a pressure of $100 \mathrm{MPa}$ until cooling. Both test results of hardness and impact resistance show a linear increase with increasing the content of $\mathrm{SiC}$ particle reinforcements.

In the work of Onat et al. [78], $\mathrm{Al}-4.5 \% \mathrm{Cu}$ was reinforced by $\mathrm{SiC}$ particulate and prepared by squeeze casting. $\mathrm{SiC}$ particulate with 5,10 , and $15 \mathrm{vol} \%$ was heated at a temperature of $700^{\circ} \mathrm{C}$. The composite melt was then poured into the preheated die and solidified under $100 \mathrm{MPa}$. Finally, increased hardness values of the composite were observed with increasing the volume percentage of $\mathrm{SiC}$ reinforcements and lower values of the gravity die casted alloy were recorded than the squeeze cast. And optimal yield and UTS values of the composite were observed when $10 \mathrm{vol} \%$ of $\mathrm{SiC}$ reinforcement was incorporated into the matrix alloy. Similar to this, Al- $4.55 \% \mathrm{Cu}$ was reinforced by $15 \mathrm{wt} \%$ of $\mathrm{SiC}$ particulate filler with the identical experimental setup. Increased hardness value and lower UTS of the composite were observed as compared to the matrix alloy [79]. And the effect of $\mathrm{ZrSiO}_{4}$ reinforcement (in the range of 5 to $25 \mathrm{wt} \%$ ) was studied on $\mathrm{Al}-4.55 \% \mathrm{Cu}$ alloy matrix prepared by squeeze casting [75]. Preheated reinforcing particles were added to the molten matrix, poured, and solidified with a squeezing load of $10 \mathrm{MPa}$. Hardness, apparent porosity, yield strength, and UTS of the composite were increased by $107.65 \%$, $34.2 \%, 156.52 \%$, and $155.8 \%$, respectively, when $15 \mathrm{wt} \%$ $\mathrm{ZrSiO}_{4}$ reinforcing particulates were incorporated. But a $43.16 \%$ decrease in impact strength of the composite was recorded with an increase in the content of reinforcing particles. Moreover, $\mathrm{Al}-4 \mathrm{wt} \% \mathrm{Cu}$ alloy was reinforced by FA particulates [80]. Preheated FA particulates with 3 and $5 \mathrm{wt} \%$ were used to make the composite by squeeze casting. The liquid composite melt was poured into the preheated die cavity, squeezed under $120 \mathrm{MPa}$ load, and solidified inside the mould. Final mechanical property test results show that a linear increase in hardness, yield strength, and UTS of the composites was gained by increasing the content of FA particles. Also, preheated FA particles (12 to $12.5 \mathrm{wt} \%$ ) were used to reinforce 1490 LM6 aluminium alloy [81]. The composite slurry was poured into the preheated steel die and squeezed using external pressure, 30 bar. Mechanical property results of the composite depict that increasing the weight percentage of FA particles yields a continuous increase in hardness. The reason for this was due to the compaction of the addition of hard FA particles and the applied squeezing pressure while fabrication.

Apart from these, squeeze cast $\mathrm{A} 356 / \mathrm{B}_{4} \mathrm{C}$ particulate reinforced composite was prepared [82]. $\mathrm{B}_{4} \mathrm{C}$ particles with $5,7.5,10,12.5$, and $15 \mathrm{vol} \%$ were used. The composite slurry was poured into the preheated die, and solidification takes place under a pressure of $80 \mathrm{MPa}$. And the as-cast samples were treated in agreement to $\mathrm{T}_{6}$. Finally, improved hardness value of the composite was gained by increasing the volume percentage of $\mathrm{B}_{4} \mathrm{C}$ reinforcements attributing that reinforcing particulates hinder the movement of dislocations. Also, a substantial improvement in the UTS of the composite was gained when $10 \mathrm{vol} \%$ of $\mathrm{B}_{4} \mathrm{C}$ particles was incorporated and the extra addition of $\mathrm{B}_{4} \mathrm{C}$ particles showed a decreased strength of the composite.

2.6. Liquid Infiltration. Liquid infiltration is one of the main important method used to produce small composite materials/components with acceptable surface finish and shape with minimum cost [83]. Infiltration is a composite manufacturing process that a fluid substitutes some other fluid which may be a gas or open-pore area of a solid material. And in infiltration processes, porous ceramic preforms; the base and the structure of the final composite 


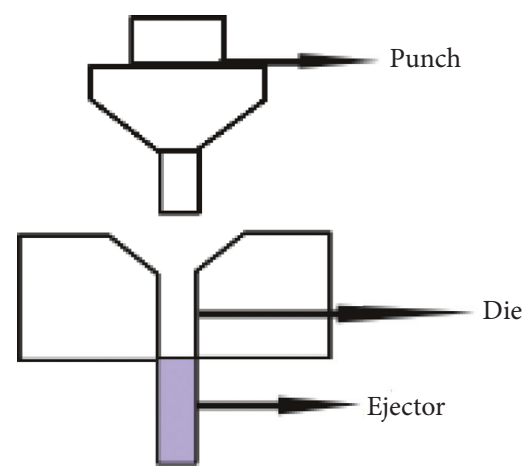

(a)

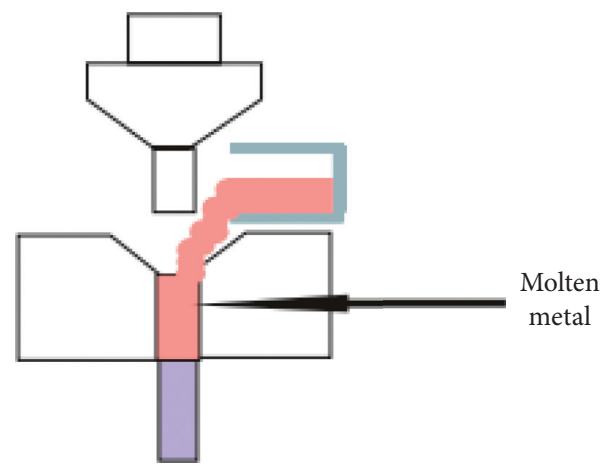

(b)

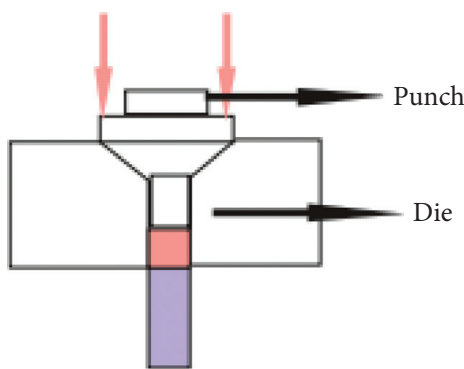

(c)

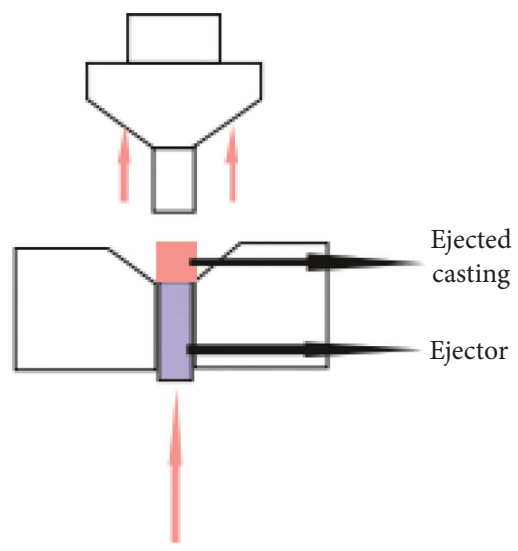

(d)

Figure 5: Schematic showing the sequence of steps during squeeze casting operation. (a) Preheated die and punch. (b) Molten metal poured into the die cavity. (c) Application of squeeze pressure. (d) Ejection of solidified casting [75].

material which defines its final shape and geometry are infiltrated with a liquid matrix material $[84,85]$. In doing so, to achieve the infiltration process, there should be an extraneous propelling force. This means that either pressure infiltration (a gas overpressure is employed on the outer surface of the liquid material), or pressureless infiltration (the preformed porous reinforcement is outgassed to atmosphere), or vacuum infiltration (the preform is vented in a vacuum) is used [86]. Figure 6 elaborates the schematic representation of the infiltration system used in the manufacturing of MMCs.

Pertinent to this, preceramic polymer attached $\mathrm{SiC}$ preforms were pressure infiltrated with pure aluminium and $\mathrm{AlCu} 4 \mathrm{Mg} 1 \mathrm{Ag} 0.5$. Preforms were compacted at different pressures 40,100 , and $200 \mathrm{MPa}$ and heated to $750^{\circ} \mathrm{C}$ before the infiltration of superheated aluminium melt. Final test results of this show that increased bending strength and stiffness of the composite were gained when $60 \mathrm{wt} \% \mathrm{SiC}$ preforms were used for both matrix compositions [87]. Also, Al2024 were vacuum infiltrated to $\mathrm{SiC}$ preforms with $0.5,1$, 2 , 3, and $4 \mathrm{vol} \%$ [86]. The manufactured composites were brought to the $T_{7}$ heat treatment process. Hardness test results of this depict that, in both heat-treated and as-cast conditions, a continued increase in the hardness of the composite with added $\mathrm{SiC}$ reinforcements was recorded. The reason for this was ascribed due to the presence of minimal porosity and hard $\mathrm{SiC}$ reinforcing particles. And here, the hardness value of the as-cast composites was lower than the heat-treated $\left(\mathrm{T}_{7}\right)$. MgO preforms (10-40 vol\%) were also infiltrated with pure aluminium using a vacuum infiltration technique [88]. Mechanical property test result values depict that a continuous increase in hardness of the composite was observed with increasing the composition of $\mathrm{MgO}$ reinforcement preforms. In addition, uniform dispersion of $\mathrm{MgO}$ particles and an increase in tensile strength of the composites having 20vol\% $\mathrm{MgO}$ were observed. Moreover, AA6061 alloy/carbon fibre composite was produced by the centrifugal infiltration process [89]. Preforms were heated to $60^{\circ} \mathrm{C}$ for 14 hours to avoid sodium silicate binder. The lower hardness value of the composite than the matrix was observed and it was attributed due to the existence of hard phases from nickel coatings and segregation of alloying constituents.

Compressive properties of A353/FA cenosphere composites were synthesised by the pressure infiltration process [90]. Hollow FA particles, higher volume fractions (57wt\%), and lower than $35 \mathrm{wt} \%$ were used to fabricate the composites with lower FA contents. A decrease in compressive strength (from 75 to $64 \mathrm{MPa}$ ) was observed when the composition of reinforcing particles increased from 20 to $35 \mathrm{wt} \%$. It was concluded that the compressive strength and modulus of the composites increased with increasing particle size, melting temperature, and employed pressure. Also, pure aluminium matrix syntactic foam/ceramic hollow sphere grades (SL300 


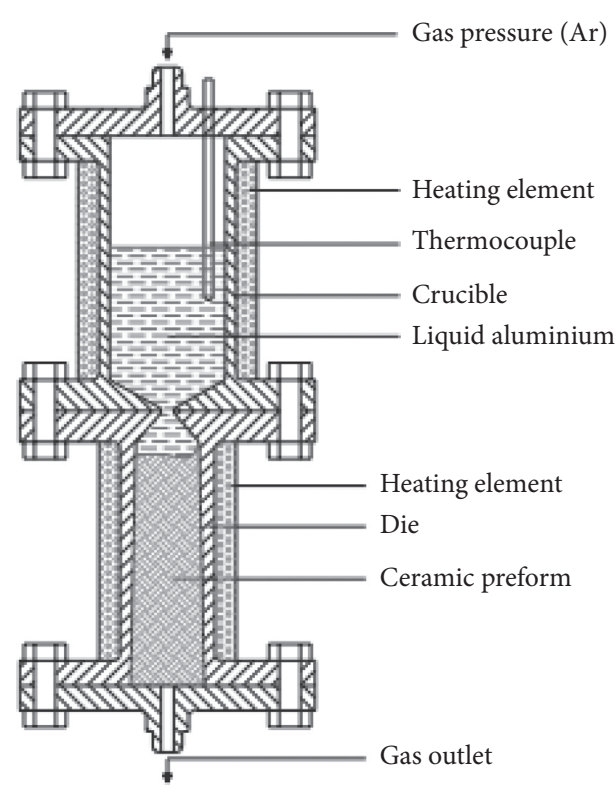

FIGURE 6: Schematic representation of the infiltration system [84].

and $\mathrm{G}$ grade hollow sphere) composites were developed by the pressure infiltration route [91]. And composites with smaller hollow spheres (S grade) show improved compressive strength and stability than the lower grade spheres. This was attributed because the smaller wall thickness reinforcements is not amenable for deflection.

2.7. Spray Codeposition Process. A substantial interest is given to spray codeposition processes to manufacture metal matrix composites containing discontinuous reinforcing materials. It is done by combining the matrix and reinforcement through which the matrix holds liquid and solid phases together [92]. Practically, it is performed by atomizing the molten metal using high-speed gas streams/jets and at the same time supplying particulate reinforcements to the spraying zone before reaching the deposition substrate. Figure 7 describes how spray codeposition takes place. It shows the matrix alloy is heated to its melting temperature which is located at the top of the atomizer and then driven to the atomizing region. Inert gas is continuously provided within a pipe to finely spray the liquid metal and to protect it from oxidation. Simultaneously, the designed amount of particulate reinforcement is provided to the liquid matrix stream moving down. After this, a two-phase mix droplet will accelerate and reach the deposition substratum for which it consolidates and creates a deposit/sediment which is basically called a porous composite preform [93, 94]. To avoid these wide pore areas, secondary manufacturing techniques such as rolling and extrusion are applied to enhance its microstructural and mechanical properties.

Research works evidently stated that spray codeposition is advantageous in that it would help to eliminate problems associated with casting processes such as thermal and intense macrosegregation problems. Moreover, it is not necessary to use fine reactive particles which are essential for powder metallurgy processing methods $[92,95]$.
In the work of Srivastava et al. [95], Al2014 was melted to a temperature of $735^{\circ} \mathrm{C}$ and reinforced by $\mathrm{SiC}$ powder of size 30 to $60 \mu \mathrm{m}$ and from 10 to 30 mass fraction of melt flow rate by spray codeposition route. Molten metal was sprayed by nitrogen gas, and at the same time, $\mathrm{SiC}$ reinforcing particles were allowed to flow to the atomization area. The powder flow rate at the bottom, middle, and top of the billet was varied with 10 , 20 , and 30 powder-to-melt mass flow ratio, respectively. First, the samples were hot rolled at a temperature of $500^{\circ} \mathrm{C}$. The samples were then aged at various temperatures $(140,170$, and $200^{\circ} \mathrm{C}$ ) after water quenching and solution treatment (at a temperature of $502^{\circ} \mathrm{C}$ ), respectively. Hardness test results of this witness that the improved hardness of the composite having $11 \mathrm{vol} \% \mathrm{SiC}$ with a particle size of $30 \mu \mathrm{m} 213 \mathrm{HV}$ later on ageing for 8 hours at $170^{\circ} \mathrm{C}$ was recorded as compared to $169 \mathrm{HV}$ of the matrix alloy. Also, an increase in tensile strength and elastic modulus and a decrease in ductility with no significant change in UTS of the composites were observed. This was attributed due to the existence of bond breaking at the interface of the matrix and reinforcing particles. In another experimental work, Al8009/SiC (mean size of about $12 \mu \mathrm{m}$ ) composite was processed by the spray codeposition method. Composite preform with a relative density of $85 \%$ was made into tubes by machining followed by wedge pressing [96]. Deposited preforms were heat-treated at $480^{\circ} \mathrm{C}$ for $40 \mathrm{~min}$ before wedging. It was then treated at a temperature of $480^{\circ} \mathrm{C}$ for about 20 minutes after wedging (a $41 \%$ reduction in thickness). This was done to avoid internal stress and strain hardening of the preforms. Test results of this depict that a nonuniform distribution of pores and reinforcements was observed before wedging that it was alleviated after wedge pressing. Due to this, the improved hardness of the wedge pressed composites was observed with an increase in thickness reduction and this was ascribed due to the removal/reduction of pores and strain hardening. Likewise, in the work of Gang et al. [97], Al8009/SiC composite preforms were fabricated by multilayer spray codeposition technique having a theoretical density of $86 \%$. SiC reinforcing particles with a mean size of $10 \mu \mathrm{m}$ and $15 \mathrm{vol} \%$ were used. The prepared composite preform was made into a cylinder by machining followed by extruding to a plate. It was then rolled between rolling mills after preheating at a temperature of $480^{\circ} \mathrm{C}$ and reheating for 20 minutes in between each rolling passes. Results depict that higher tensile strength values of the composites were recorded after the rolling of the preformed porous composite. This was revealed due to the collapsing and closing of pores, breaking of oxide films among the deposited particles, and improved dispersion of $\mathrm{SiC}$ reinforcing particles. It was reported that all these were due to extreme shear distortion existed during the hot rolling of the composite. Al- $\mathrm{Zn}-\mathrm{Mg}-\mathrm{Cu} / \mathrm{SiC}$ composite preform was manufactured by the spray codeposition technique [98]. SiC particle reinforcement with an average size of $15 \mu \mathrm{m}$ and $20 \mathrm{vol} \%$ was used. Composite preform billet was squeezed out into bars at a temperature of $420^{\circ} \mathrm{C}$ and solution treatment of the extruded samples takes place. Hardness test results of the composite show a prominent increase in microhardness when it was aged for about 28 hours at a temperature of $120^{\circ} \mathrm{C}$. In addition, dual solution-treated $\left(470^{\circ} \mathrm{C} / 1\right.$ hour $+490^{\circ} \mathrm{C} / 1$ hour $+120^{\circ} \mathrm{C} / 28$ hours $)$ composites 


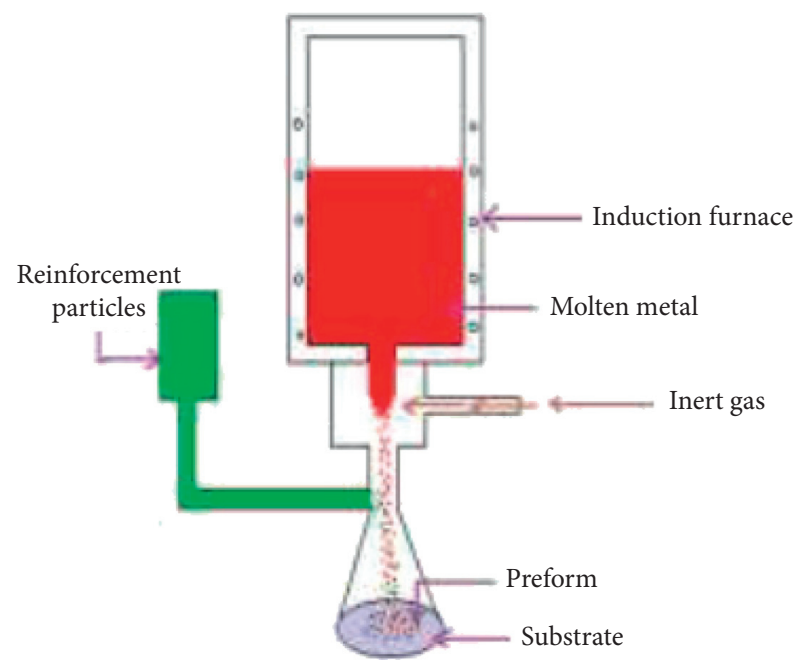

FIGURE 7: Schematic representation of the spray codeposition process [93].

have exhibited comparative improvement in tensile strength properties than the single solution-treated $\left(490^{\circ} \mathrm{C} /\right.$ 1 hour $+120^{\circ} \mathrm{C} / 28$ hours) composites. This was attributed due to the added $\mathrm{Ni}, \mathrm{Zr}$, and $\mathrm{Mn}$ and the intense solubility of alloying elements. But, as a whole, a lower tensile strength of the composites was observed than that of the matrix alloy even if the greater elastic modulus of the composites was recorded (up to $100 \mathrm{GPa}$ ). A detail elaboration of this is referred to in [98]. Moreover, related works of spray codeposited AMCs showed that AA2519-SiC/ $\mathrm{Al}_{2} \mathrm{O}_{3}$ [99], Al2024/SiC [100], Al-Li 8090/SiC [101], and AA5083/tungsten carbide (WC-CoCr), chromium carbide $\left(\mathrm{Cr}_{3} \mathrm{C}_{2}-\mathrm{NiCr}\right)$, and $\mathrm{Al}_{2} \mathrm{O}_{3}$ [102] were fabricated by spray codeposition technique and improvement in hardness and tensile strength of the composites was observed.

2.8. Reactive In Situ Processes. Generally, in reactive in situ AMCs manufacturing processes, the reinforcing element (ceramic particle) is formed by chemically reacting with the matrix alloy which is part of the final composite. The matrix and mostly organic salts or master alloys are permitted to chemically react to create the reinforcing component which is achieved exothermically. To form the desired quantity of reinforcing particle in the composite, a designed amount of master alloy or combination of inorganic salts should be incorporated and mixed with the base matrix. In doing so, working parameters such as particle size of reinforcing particles, melting and sintering temperatures, holding time, and pressure and secondary manufacturing processes such as forging and rolling have a profound effect on the physical and mechanical property of the final composite. The basic advantage of the reactive in situ processing route is that wetting of reinforcing particles is not a problem and a composite having comparatively clean and hard interfaces among the matrix and reinforcement could be developed easily $[13,103]$.

Al6063 alloy was reinforced by $\mathrm{TiB}_{2}$ particles utilising $\mathrm{Al}-3 \mathrm{wt} \% \mathrm{~B}$ and $\mathrm{Al}-10 \mathrm{wt} \% \mathrm{Ti}$ principal alloys. Alloys were melted in a furnace by varying the content of Al-10Ti from 10 to $20 \mathrm{wt} \%$ to a temperature of $800^{\circ} \mathrm{C}$ to crate $\mathrm{TiB}_{2}(4.29$, 9.15 , and $13.12 \mathrm{wt} \%$ ) reinforcing particles by in situ reaction technique [104]. It was then cleaned and poured to the prepared moulds. Final in situ prepared composite mechanical property results showed a remarkable increase in all features (both macro- and microhardness, UTS, elastic modulus, and ductility of the composite). And a detailed reason for these improvements is attributed because the added ceramic particles create a greater number of dislocation densities which are able to resist the applied load and grain refining capability of boron. In other research works, AA7075 alloy was melted to a temperature of $850^{\circ} \mathrm{C}$ and inorganic salts such as $\mathrm{K}_{2} \mathrm{TiF}_{6}$ and $\mathrm{KBF}_{4}$ were added to create $\mathrm{TiB}_{2}$ reinforcing particles by in situ reaction technique [105]. Inorganic salts were incorporated into the molten metal and stirred for 40 minutes. Then the composite melt was poured to a preheated die, and composite castings were produced containing $0,3,6$, and $9 \mathrm{wt} \% \mathrm{TiB}_{2}$ reinforcing particles. Result to this, a defect-free composite, free from shrinkages, slag inclusions, and porosity, was fabricated. With increasing the content of $\mathrm{TiB}_{2}$ particulates, an increase in hardness and UTS and a decrease in ductility of the composite were observed. The reason for this was attributed due to grain refinement of the aluminium alloy due to the formed $\mathrm{TiB}_{2}$ particulates. And a more elaborated discussion of this result can be referred to in the original paper. Similarly, AA 7075 alloy was reinforced by $\mathrm{ZrB}_{2}$ particles which were created by in situ reaction of $\mathrm{KBF}_{4}$ and $\mathrm{K}_{2} \mathrm{ZrF}_{6}$ inorganic salts [106]. The designed amount of $\mathrm{KBF}_{4}$ and $\mathrm{K}_{2} \mathrm{ZrF}_{6}$ inorganic salts was added to the matrix melt, stirred for 40 minutes, and poured into a preheated casting die. Final composite castings having 0, 3, 6, and $9 \mathrm{wt} \%$ of $\mathrm{ZrB}_{2}$ reinforcing particles were fabricated. Results show that the in situ created $\mathrm{ZrB}_{2}$ reinforcing particles outstandingly have enhanced macro and microhardness and tensile strength of the composite. It was depicted that a linear increase in both hardness values and tensile strength property was gained by increasing the content of $\mathrm{ZrB}_{2}$ particles. And hindrance of the motion of dislocations, grain refinement, uniform distribution of $\mathrm{ZrB}_{2}$ particles, and proper interfacial bonding is depicted for these improvements. Also, in the work of Mohanavel et al. [107], $\mathrm{ZrB}_{2}$ particles were created by the exothermic reaction of inorganic salts such as $\mathrm{KBF}_{4}$ and $\mathrm{K}_{2} \mathrm{ZrF}_{6}$ in order to reinforce AA2014 alloy. Inorganic salts were added with the matrix melt, stirred for 20 minutes, and poured into the preheated moulds. Both macro and microhardness values of the composite were increased linearly with increasing the content of $\mathrm{ZrB}_{2}$ reinforcing particles. The reason for this was attributed due to the virtually uniform dispersion of reinforcing particles and the existence of proper bonding among the matrix and $\mathrm{ZrB}_{2}$ particles. A similar increasing trend was observed for tensile strength testing of the composite as well. And a substantial number of dislocation densities and Orowan strengthening concepts are attributed for this improved property of the composite.

AA6061/TiC composite was fabricated by in situ reaction technique using $\mathrm{K}_{2} \mathrm{TiF}_{6}$ and preheated $\mathrm{SiC}$ powder [108]. 
$\mathrm{K}_{2} \mathrm{TiF}_{6}$ and preheated $\mathrm{SiC}$ were added to the matrix melt, stirred for 60 minutes intermittently, and taken to the die casting process. Final composite castings containing 0, 2.5, and $5 \mathrm{wt} \%$ of $\mathrm{TiC}$ reinforcing particles were prepared. Uniform distribution of TiC particles and good bonding of clusters were observed. Also, an outstanding increase in UTS (21\%) and microhardness $(83 \%)$ of the composites was gained for the case of AA6061/5wt\% TiC compositions. The reason for these was ascribed as the in situ formed $\mathrm{TiC}$ particulates are able to hinder the motion of dislocations and crack propagation while loading. However, the ductility of the composite was decreased linearly with increasing the amount of $\mathrm{TiC}$ reinforcing particles. Previous to this, identical research work was done by Dinaharan et al. [109] using $0,2.5,5,7.5$, and $10 w t \% \mathrm{ZrB}_{2}$ particles, but a lower mechanical property of the composite was recorded. Likewise, AA6061 alloy was reinforced with $\mathrm{TiC}$ particles which were created by in situ reaction of $\mathrm{F}_{6} \mathrm{~K}_{2} \mathrm{Ti}$ and pure graphite with the liquid matrix [110]. First, the matrix and $\mathrm{F}_{6} \mathrm{~K}_{2} \mathrm{Ti}$ were mixed and melted to a temperature of $900^{\circ} \mathrm{C}$. Then graphite powders were incorporated into the molten mix being agitated with a rotating blade at $300 \mathrm{rpm}$ and taken to the preheated moulds for casting. Composite melts were then heated to $500^{\circ} \mathrm{C}$ and taken to the forging process. Results of this show that both the as-cast and forged composite samples exhibit increased hardness properties. However, the hardness value of the hot-forged composites was improved with a much significant value with increasing the content of $\mathrm{TiC}$ particles $(55.05 \%$ for $5 \mathrm{wt} \%$ and $79.72 \%$ for $10 \mathrm{wt} \%$ of TiC particles). Similarly, a $79 \%$ increase in tensile strength of the forged composites was obtained for $10 \mathrm{wt} \%$ of $\mathrm{TiC}$ composite even if there was a concomitant decrease in ductility of the composite with increasing $\mathrm{TiC}$ particles. In addition to these, Al6061 was also reinforced with $\mathrm{Al}_{3} \mathrm{Ti}$ particle by in situ reaction of $\mathrm{F}_{6} \mathrm{~K}_{2} \mathrm{Ti}$ with the matrix alloy [111]. $\mathrm{F}_{6} \mathrm{~K}_{2} \mathrm{Ti}$ salt with 5,10 , and $15 \mathrm{wt} \%$ was added to the melt to fabricate composites with 2.7, 5.4, and $8.1 \mathrm{wt} \%$ reinforcing $\mathrm{Al}_{3} \mathrm{Ti}$ particles. After stirring the melt for 2 minutes, ultrasonication was done at a temperature of $750^{\circ} \mathrm{C}$, and finally, the melt was poured into the metallic mould. A linear increase in hardness, tensile strength, and elongation property of the composite was observed with increasing the content of $\mathrm{Al}_{3} \mathrm{Ti}$ reinforcing particles. The reason for these improvements was attributed due to thermal twin and Hall-Petch strengthening mechanisms.

Also, AMC was prepared from aluminium powder of high purity and 1, 2, and $3 \mathrm{vol} \%$ of tungsten powder to create Al12W reinforcing particles [112]. The composite was manufactured by reaction sintering technique with its solid state. Composite powder mixtures were consolidated to a pellet under a load of $20 \mathrm{MPa}$. It was then sintered and extruded at a temperature of $500^{\circ} \mathrm{C}$. The final tensile strength property of the composite depicts that a significant increase in UTS, a little increase in yield strength, and a decrement in ductility of the composite were observed. The reason for this was stated due to the high load-carrying capacity of the created strong Al12W particles which help for the efficient transfer of load and the existence of greater dislocation tightness. Plus, $\mathrm{Al} 2024$ and $\mathrm{ZrO}_{2}$ powders were mixed and milled to get in situ $\mathrm{Al}_{3} \mathrm{Zr}$ and nano- $\mathrm{Al}_{2} \mathrm{O}_{3}$ reinforced $\mathrm{Al} 2024$ matrix composite by utilising reactive sintering technique [113]. Milled powders were taken to graphite moulds and sintered at a temperature of $600^{\circ} \mathrm{C}$ for 60 minutes with a pressure of $25 \mathrm{MPa}$. The effects of sintering parameters (temperature, holding time, and pressure) on the mechanical property of the composites were analysed. Tensile strength property test of the composite revealed that the composite sintered at a temperature of $840^{\circ} \mathrm{C}$ for 60 minutes under $25 \mathrm{MPa}$ showed a higher strength relative to the as-sintered $\mathrm{Al} 2024 / \mathrm{ZrO}_{2}$ composite. The reason for this was ascribed due to the formation of $\mathrm{Al}_{2} \mathrm{O}_{3}$ nanoparticles and $\mathrm{Al}_{3} \mathrm{Zr}$ particles accompanying a network structure.

\section{Conclusions}

(1) Obviously, it is seen that the weak mechanical properties of pure aluminium and its alloys can be improved to a significant level by adding a variety of reinforcing materials even if there is a slight decrease in ductility of the final composite.

(2) AMCs have a wide range of applications almost in all manufacturing, construction, automotive, and aerospace industries at large due to their distinct and fabulous material properties than other engineering materials.

(3) AMCs can be processed in different techniques which depend on the type of processing equipment, type, size, and shape of the reinforcement material, processing parameters, and application area of the composite.

(4) Generally, using FSP and SPS methods to manufacture AMCs is advantageous in that the final composite material will have better mechanical properties since the presence of defects arising due to poor processing methods is avoided or minimized to a great extent without affording high processing cost.

(5) It can be concluded that almost all composite materials manufactured by spray codeposition route are $\mathrm{SiC}$ particle reinforced. Based on this, future research works can be held using other particulate reinforcements by utilising the spray codeposition route and are able to compare their research outcome with the previously $\mathrm{SiC}$ reinforced AMCs.

(6) The weak mechanical properties of aluminium alloys (yield strength, UTS, and hardness characteristics) can be improved well by adding hybrid reinforcements and ceramic reinforcing particulates than using agroderivatives to gain a composite having a comparable strength with other ferrous metallic materials such as iron and steel.

\section{Conflicts of Interest}

The author declares that there are no conflicts of interest regarding the publication of this paper. 


\section{Acknowledgments}

The author would like to express a deep sense of gratitude to Dr. Samson Mekbib for his guidance in doing this review paper.

\section{References}

[1] R. Purohit, M. M. U. Qureshi, and B. Kumar, "Effect of forging on aluminum matrix nano composites: a review," Materials Today: Proceedings, vol. 4, no. 4, pp. 5357-5360, 2017.

[2] N. Panwar and A. Chauhan, "Fabrication methods of particulate reinforced Aluminium metal matrix composite-a review," Materials Today: Proceedings, vol. 5, no. 2, pp. 5933-5939, 2018.

[3] K. Vineeth Kumar and L. Jayahari, "Study of mechanical properties and wear behaviour of aluminium 6063 matrix composites reinforced with steel machining chips," Materials Today: Proceedings, vol. 5, no. 9, pp. 20285-20291, 2018.

[4] A. Pramanik, "Effects of reinforcement on wear resistance of aluminum matrix composites," Transactions of Nonferrous Metals Society of China, vol. 26, no. 2, pp. 348-358, 2016.

[5] S. P. Rawal and B. Al, "Metal-matrix composites for space applications," Jom, vol. 53, no. 4, pp. 14-17, 2001.

[6] P. Rohatgi, "Cast aluminum-matrix composites for automotive applications," Jom, vol. 43, no. 4, pp. 10-15, 1991.

[7] A. Vedrtnam and A. Kumar, "Fabrication and wear characterization of Silicon Carbide and Copper reinforced Aluminium matrix composite," Materials Discovery, vol. 9, pp. 16-22, 2017.

[8] S. Selvakumar, I. Dinaharan, R. Palanivel, and B. G. Babu, "Development of stainless steel particulate reinforced AA6082 aluminum matrix composites with enhanced ductility using friction stir processing," Materials Science and Engineering A, vol. 685, 2016.

[9] J. Sethi, S. Das, and K. Das, "Study on thermal and mechanical properties of yttrium tungstate-aluminium nitride reinforced aluminium matrix hybrid composites," Journal of Alloys and Compounds, vol. 774, no. 1, pp. 848-855, 2019.

[10] C. Hima Gireesh, K. G. Durga Prasad, K. Ramji, and P. V. Vinay, "Mechanical characterization of aluminium metal matrix composite reinforced with aloe vera powder," Materials Today: Proceedings, vol. 5, no. 2, pp. 3289-3297, 2018.

[11] G. R. Li, J. F. Cheng, H. M. Wang, and C. Q. Li, "The influence of cryogenic-aging circular treatment on the microstructure and properties of aluminum matrix composites," Journal of Alloys and Compounds, vol. 695, pp. 1930-1945, 2017.

[12] U. Pandey, R. Purohit, P. Agarwal, S. K. Dhakad, and R. S. Rana, "Effect of TiC particles on the mechanical properties of aluminium alloy metal matrix composites (MMCs)," Materials Today: Proceedings, vol. 4, no. 4, pp. 5452-5460, 2017.

[13] K. K. Chawla, Metal Matrix Composites, Springer Science+Business Media, Inc., Berlin, Germany, 2006.

[14] B. R. Reddy and C. Srinivas, "Fabrication and characterization of silicon carbide and fly ash reinforced aluminium metal matrix hybrid composites," Materials Today: Proceedings, vol. 5, no. 2, pp. 8374-8381, 2018.

[15] S. Gopalakrishnan and N. Murugan, "Production and wear characterisation of AA 6061 matrix titanium carbide particulate reinforced composite by enhanced stir casting method," Composites Part B: Engineering, vol. 43, no. 2, pp. 302-308, 2012.

[16] M. Singla, D. D. Dwivedi, L. Singh, and V. Chawla, "Development of aluminium based silicon carbide particulate metal matrix composite," Journal of Minerals and Materials Characterization and Engineering, vol. 8, no. 6, pp. 455-467, 2009.

[17] A. Dehghan Hamedan and M. Shahmiri, "Production of A356-1wt\% SiC nanocomposite by the modified stir casting method," Materials Science and Engineering A, vol. 556, pp. 921-926, 2012.

[18] R. Taherzadeh Mousavian, R. Azari Khosroshahi, S. Yazdani, D. Brabazon, and A. F. Boostani, "Fabrication of aluminum matrix composites reinforced with nano to micrometer-sized SiC particles," Materials \& Design, vol. 89, pp. 58-70, 2016.

[19] H. R. Ezatpour, M. Torabi-Parizi, and S. A. Sajjadi, "Microstructure and mechanical properties of extruded $\mathrm{Al} /$ $\mathrm{Al}_{2} \mathrm{O}_{3}$ composites fabricated by stir-casting process," Transactions of Nonferrous Metals Society of China, vol. 23, no. 5, pp. 1262-1268, 2013.

[20] K. M. Shorowordi, T. Laoui, A. S. M. A. Haseeb, J. P. Celis, and L. Froyen, "Microstructure and interface characteristics of $\mathrm{B}_{4} \mathrm{C}, \mathrm{SiC}$ and $\mathrm{Al}_{2} \mathrm{O}_{3}$ reinforced $\mathrm{Al}$ matrix composites: a comparative study," Journal of Materials Processing Technology, vol. 142, no. 3, pp. 738-743, 2003.

[21] A. Baradeswaran and A. Elaya Perumal, "Influence of $\mathrm{B}_{4} \mathrm{C}$ on the tribological and mechanical properties of $\mathrm{Al} 7075-\mathrm{B}_{4} \mathrm{C}$ composites," Composites Part B: Engineering, vol. 54, no. 1, pp. 146-152, 2013.

[22] M. Kok, "Production and mechanical properties of $\mathrm{Al}_{2} \mathrm{O}_{3}$ particle-reinforced 2024 aluminium alloy composites," Journal of Materials Processing Technology, vol. 161, no. 3, pp. 381-387, 2005.

[23] J. J. Moses, I. Dinaharan, and S. J. Sekhar, "Prediction of influence of process parameters on tensile strength of AA6061/TiC aluminum matrix composites produced using stir casting," Transactions of Nonferrous Metals Society of China, vol. 26, no. 6, pp. 1498-1511, 2016.

[24] R. D. Manikonda, S. Kosaraju, K. A. Raj, and N. Sateesh, "Wear behavior analysis of silica carbide based aluminum metal matrix composites," Materials Today, vol. 5, no. 9, 2010.

[25] U. R. Kanth, P. S. Rao, and M. G. Krishna, "Mechanical behaviour of fly ash/SiC particles reinforced Al-Zn alloybased metal matrix composites fabricated by stir casting method," Journal of Materials Research and Technology, vol. 8, no. 1, pp. 737-744, 2019.

[26] V. K. Sharma, R. C. Singh, and R. Chaudhary, "Effect of flyash particles with aluminium melt on the wear of aluminium metal matrix composites," Engineering Science and Technology, an International Journal, vol. 20, no. 4, pp. 1318-1323, 2017.

[27] A. Mazahery, H. Abdizadeh, and H. R. Baharvandi, "Development of high-performance A356/nano- $\mathrm{Al}_{2} \mathrm{O}_{3}$ composites," Materials Science and Engineering: A, vol. 518, no. 12, pp. 61-64, 2009.

[28] M. K. Akbari, K. Shirvanimoghaddam, Z. Hai, S. Zhuiykov, and $\mathrm{H}$. Khayyam, "Al- $\mathrm{TiB}_{2}$ micro/nanocomposites: particle capture investigations, strengthening mechanisms and mathematical modelling of mechanical properties," Materials Science and Engineering A, vol. 682, 2017.

[29] K. Shirvanimoghaddam, H. Khayyam, H. Abdizadeh et al., "Effect of $\mathrm{B}_{4} \mathrm{C}, \mathrm{TiB}_{2}$ and $\mathrm{ZrSiO}_{4}$ ceramic particles on mechanical properties of aluminium matrix composites: 
experimental investigation and predictive modelling," Ceramics International, vol. 42, no. 5, pp. 6206-6220, 2016.

[30] K. K. Alaneme, A. V. Fajemisin, and N. B. Maledi, "Development of aluminium-based composites reinforced with steel and graphite particles: structural, mechanical and wear characterization," Journal of Materials Research and Technology, vol. 8, no. 1, pp. 670-682, 2019.

[31] Y. Pazhouhanfar and B. Eghbali, "Microstructural characterization and mechanical properties of $\mathrm{TiB}_{2}$ reinforced Al6061 matrix composites produced using stir casting process," Materials Science and Engineering A, vol. 710, 2018.

[32] H. R. Lashgari, S. Zangeneh, H. Shahmir, M. Saghafi, and M. Emamy, "Heat treatment effect on the microstructure, tensile properties and dry sliding wear behavior of A356-10\% $\mathrm{B}_{4} \mathrm{C}$ cast composites," Materials \& Design, vol. 31, no. 9, pp. 4414-4422, 2010.

[33] F. Toptan, A. Kilicarslan, A. Karaaslan, M. Cigdem, and I. Kerti, "Processing and microstructural characterisation of AA 1070 and AA 6063 matrix $\mathrm{B}_{4} \mathrm{Cp}$ reinforced composites," Materials \& Design, vol. 31, no. 1, pp. S87-S91, 2010.

[34] M. Uthayakumar, S. Aravindan, and K. Rajkumar, "Wear performance of $\mathrm{Al}-\mathrm{SiC}-\mathrm{B}_{4} \mathrm{C}$ hybrid composites under dry sliding conditions," Materials \& Design, vol. 47, pp. 456-464, 2013.

[35] S. Suresha and B. K. Sridhara, "Wear characteristics of hybrid aluminium matrix composites reinforced with graphite and silicon carbide particulates," Composites Science and Technology, vol. 70, no. 11, pp. 1652-1659, 2010.

[36] G. B. Veeresh Kumar, C. S. P. Rao, and N. Selvaraj, "Studies on mechanical and dry sliding wear of Al6061-SiC composites," Composites Part B: Engineering, vol. 43, no. 3, pp. 1185-1191, 2012.

[37] K. Shirvanimoghaddam, S. U. Hamim, M. Karbalaei Akbari et al., "Carbon fiber reinforced metal matrix composites: fabrication processes and properties," Composites Part A: Applied Science and Manufacturing, vol. 92, pp. 70-96, 2017.

[38] G. Li, Y. Qu, Y. Yang, Q. Zhou, X. Liu, and R. Li, "Improved multi-orientation dispersion of short carbon fibers in aluminum matrix composites prepared with square crucible by mechanical stirring," Journal of Materials Science \& Technology, vol. 40, pp. 81-87, 2020.

[39] G. Li, "Mechanical, corrosion and cavitation erosion properties of LM 9 grade aluminium-multi-walled carbon nanotubes composites," Australian Journal of Mechanical Engineering, vol. 6, no. 2, pp. 1-10, 2020.

[40] S. Suhas, J. Quadros, and N. L. Vaishak, "Evaluation and characterization of tensile properties of short coated carbon fiber reinforced Aluminium7075 alloy metal matrix composites via liquid stir casting method," Material Science Research India, vol. 13, no. 2, pp. 66-73, 2016.

[41] R. S. Mishra and Z. Y. Ma, "Friction stir welding and processing," Materials Science and Engineering: R: Reports, vol. 50, no. 1-2, pp. 1-78, 2005.

[42] W. Wang, Q.-y. Shi, P. Liu, H.-k. Li, and T. Li, “A novel way to produce bulk $\mathrm{SiCp}$ reinforced aluminum metal matrix composites by friction stir processing," Journal of Materials Processing Technology, vol. 209, no. 4, pp. 2099-2103, 2009.

[43] M. S. Wegglowski, "Friction stir processing-state of the art," Archives of Civil and Mechanical Engineering, vol. 18, no. 1, pp. 114-129, 2018.

[44] G. Huang, Y. Shen, R. Guo, and W. Guan, "Fabrication of tungsten particles reinforced aluminum matrix composites using multi-pass friction stir processing: evaluation of microstructural, mechanical and electrical behavior," $M a$ terials Science and Engineering: A, vol. 674, pp. 504-513, 2016.

[45] M. Puviyarasan and C. Praveen, "Fabrication and analysis of bulk SiCp reinforced aluminum metal matrix composites using friction stir process," International Journal of $\mathrm{Me}$ chanical, Aerospace, Industrial, vol. 5, no. 10, pp. 2052-2056, 2011.

[46] A. Thangarasu, N. Murugan, I. Dinaharan, and S. J. Vijay, "Synthesis and characterization of titanium carbide particulate reinforced AA6082 aluminium alloy composites via friction stir processing," Archives of Civil and Mechanical Engineering, vol. 15, no. 2, pp. 324-334, 2015.

[47] A. Dolatkhah, P. Golbabaei, M. K. Besharati Givi, and F. Molaiekiya, "Investigating effects of process parameters on microstructural and mechanical properties of Al5052/SiC metal matrix composite fabricated via friction stir processing," Materials \& Design, vol. 37, pp. 458-464, 2012.

[48] C.-H. Jeon, Y.-H. Jeong, J.-J. Seo et al., "Material properties of graphene/aluminum metal matrix composites fabricated by friction stir processing," International Journal of Precision Engineering and Manufacturing, vol. 15, no. 6, pp. 12351239, 2014.

[49] Z. Du, M. J. Tan, J. F. Guo, G. Bi, and J. Wei, "Fabrication of a new $\mathrm{Al}-\mathrm{Al}_{2} \mathrm{O}_{3}$-CNTs composite using friction stir processing (FSP)," Materials Science and Engineering: A, vol. 667, pp. 125-131, 2016.

[50] I. Dinaharan, K. Kalaiselvan, and N. Murugan, "Influence of rice husk ash particles on microstructure and tensile behavior of AA6061 aluminum matrix composites produced using friction stir processing," Composites Communications, vol. 3, p. 42, 2016.

[51] I. Dinaharan and E. T. Akinlabi, "Low cost metal matrix composites based on aluminum, magnesium and copper reinforced with fly ash prepared using friction stir processing," Composites Communications, vol. 9, pp. 22-26, 2018.

[52] H. A. Deore, J. Mishra, A. G. Rao, H. Mehtani, and V. D. Hiwarkar, "Effect of filler material and post process ageing treatment on microstructure, mechanical properties and wear behaviour of friction stir processed AA 7075 surface composites," Surface and Coatings Technology, vol. 374, no. 1, pp. 52-64, 2019.

[53] K. S. Munir, P. Kingshott, and C. Wen, "Carbon nanotube reinforced titanium metal matrix composites prepared by powder metallurgy-a review," Critical Reviews in Solid State and Materials Sciences, vol. 40, no. 1, pp. 38-55, 2015.

[54] A. M. K. Esawi, K. Morsi, A. Sayed, A. A. Gawad, and P. Borah, "Fabrication and properties of dispersed carbon nanotube-aluminum composites," Materials Science and Engineering: A, vol. 508, no. 1-2, pp. 167-173, 2009.

[55] Z. Y. Liu, S. J. Xu, B. L. Xiao, P. Xue, W. G. Wang, and Z. Y. Ma, "Effect of ball-milling time on mechanical properties of carbon nanotubes reinforced aluminum matrix composites," Composites Part A: Applied Science and Manufacturing, vol. 43, no. 12, pp. 2161-2168, 2012.

[56] M. Jafari, M. H. Abbasi, M. H. Enayati, and F. Karimzadeh, "Mechanical properties of nanostructured Al2024-MWCNT composite prepared by optimized mechanical milling and hot pressing methods," Advanced Powder Technology, vol. 23, no. 2, pp. 205-210, 2012.

[57] R. Zheng, X. Hao, Y. Yuan, Z. Wang, K. Ameyama, and C. Ma, "Effect of high volume fraction of $\mathrm{B}_{4} \mathrm{C}$ particles on the microstructure and mechanical properties of aluminum alloy 
based composites," Journal of Alloys and Compounds, vol. 576, pp. 291-298, 2013.

[58] A. Abdollahi, A. Alizadeh, and H. R. Baharvandi, "Dry sliding tribological behavior and mechanical properties of Al2024-5wt.\% $\mathrm{B}_{4} \mathrm{C}$ nanocomposite produced by mechanical milling and hot extrusion," Materials \& Design, vol. 55, pp. 471-481, 2014.

[59] Z. Zhang, T. Topping, Y. Li et al., "Mechanical behavior of ultrafine-grained $\mathrm{Al}$ composites reinforced with $\mathrm{B}_{4} \mathrm{C}$ nanoparticles," Scripta Materialia, vol. 65, no. 8, pp. 652-655, 2011.

[60] J. Wang, Z. Li, G. Fan, H. Pan, Z. Chen, and D. Zhang, "Reinforcement with graphene nanosheets in aluminum matrix composites," Scripta Materialia, vol. 66, no. 8, pp. 594-597, 2012.

[61] C. A. V. Kumar and J. S. Rajadurai, "Influence of rutile $\left(\mathrm{TiO}_{2}\right)$ content on wear and microhardness characteristics of aluminium-based hybrid composites synthesized by powder metallurgy," Transactions of Nonferrous Metals Society of China, vol. 26, no. 1, pp. 63-73, 2016.

[62] S. Narayan and A. Rajeshkannan, "Hardness, tensile and impact behaviour of hot forged aluminium metal matrix composites," Journal of Materials Research and Technology, vol. 6, no. 3, pp. 213-219, 2017.

[63] Z. Y. Liu, K. Zhao, B. L. Xiao, W. G. Wang, and Z. Y. Ma, "Fabrication of CNT/Al composites with low damage to CNTs by a novel solution-assisted wet mixing combined with powder metallurgy processing," Materials \& Design, vol. 97, pp. 424-430, 2016.

[64] X. Pang, Y. Xian, W. Wang, and P. Zhang, “Tensile properties and strengthening effects of $6061 \mathrm{Al} / 12 \mathrm{wt} \% \mathrm{~B}_{4} \mathrm{C}$ composites reinforced with nano- $\mathrm{Al}_{2} \mathrm{O}_{3}$ particles," Journal of Alloys and Compounds, vol. 768, pp. 476-484, 2018.

[65] U. Anselmi-Tamburini, "Spark plasma sintering," Reference Module in Materials Science and Materials Engineering, vol. 768, pp. 1-17, 2019.

[66] K. Shirvanimoghaddam, E. Ghasali, A. Pakseresht et al., "Super hard carbon microtubes derived from natural cotton for development of high performance titanium composites," Journal of Alloys and Compounds, vol. 775, pp. 601-616, 2019.

[67] E. Ghasali, M. Alizadeh, K. Shirvanimoghaddam et al., "Porous and non-porous alumina reinforced magnesium matrix composite through microwave and spark plasma sintering processes," Materials Chemistry and Physics, vol. 212, pp. 252-259, 2018.

[68] Z. Károly, C. Balázsi, K. Balázsi, A. Petrik, J. Lábár, and A. Dhar, "Hybrid aluminum matrix composite prepared by spark plasm sintering," Chemical Bulletin, vol. 3, no. 3, pp. 247-250, 2014.

[69] Y. Shadangi, S. Sharma, V. Shivam et al., "Fabrication of Al$\mathrm{Cu}-\mathrm{Fe}$ quasicrystal reinforced 6082 aluminium matrix nanocomposites through mechanical milling and spark plasma sintering," Journal of Alloys and Compounds, vol. 828, p. 154258, 2020.

[70] Z. Yuan, W. Tian, F. Li, Q. Fu, Y. Hu, and X. Wang, "Microstructure and properties of high-entropy alloy reinforced aluminum matrix composites by spark plasma sintering," Journal of Alloys and Compounds, vol. 806, pp. 901-908, 2019.

[71] K. Park, J. Park, and H. Kwon, "Fabrication and characterization of Al-SUS316L composite materials manufactured by the spark plasma sintering process," Materials Science and Engineering: A, vol. 691, pp. 8-15, 2017.

[72] G. A. Sweet, M. Brochu, R. L. Hexemer, I. W. Donaldson, and D. P. Bishop, "Consolidation of aluminum-based metal matrix composites via spark plasma sintering," Materials Science and Engineering: A, vol. 648, pp. 123-133, 2015.

[73] M. Hadian, H. Shahrajabian, and M. Rafiei, "Mechanical properties and microstructure of $\mathrm{Al} /\left(\mathrm{TiC}+\mathrm{TiB}_{2}\right)$ composite fabricated by spark plasma sintering," Ceramics International, vol. 45, no. 9, pp. 12088-12092, 2019.

[74] C. Prakash, S. Singh, S. Sharma et al., "Fabrication of aluminium carbon nano tube silicon carbide particles based hybrid nano-composite by spark plasma sintering," Materials Today: Proceedings, vol. 21, no. 1, pp. 1637-1642, 2020.

[75] E. G. Okafor and V. S. Aigbodion, "Effect of zircon silicate reinforcements on the microstructure and properties of as cast $\mathrm{Al}-4.5 \mathrm{Cu}$ matrix particulate composites synthesized via squeeze cast route," Tribology in Industry, vol. 32, no. 2, pp. 31-37, 2010.

[76] Z. Yu, G. Wu, L. Jiang, and D. Sun, "Effect of coating $\mathrm{Al}_{2} \mathrm{O}_{3}$ reinforcing particles on the interface and mechanical properties of 6061 alloy aluminium matrix composites," Materials Letters, vol. 59, no. 18, pp. 2281-2284, 2005.

[77] M. Singh, L. Natrayan, and M. Senthil Kumar, "An experimental investigation on mechanical behaviour of SiCp reinforced Al 6061 MMC using squeeze casting process," International Journal of Mechanical and Production Engineering Research, vol. 7, no. 6, pp. 663-668, 2017.

[78] A. Onat, H. Akbulut, and F. Yilmaz, "Production and characterisation of silicon carbide particulate reinforced aluminium-copper alloy matrix composites by direct squeeze casting method," Journal of Alloys and Compounds, vol. 436, no. 1-2, pp. 375-382, 2007.

[79] A. Onat, "Mechanical and dry sliding wear properties of silicon carbide particulate reinforced aluminium-copper alloy matrix composites produced by direct squeeze casting method," Journal of Alloys and Compounds, vol. 489, no. 1, pp. 119-124, 2010.

[80] S. Mohan Kumar, S. Srinivas, M. Ramachandra, and K. V. Mahendra, "Characterization of aluminium metal matrix composite produced by squeeze casting technique," Materials Today: Proceedings, vol. 5, no. 10, pp. 22718-22726, 2018.

[81] K. N. P. Prasad and M. Ramachandra, "Determination of abrasive wear behaviour of Al-fly ash metal matrix composites produced by squeeze casting," Materials Today: Proceedings, vol. 5, no. 1, pp. 2844-2853, 2018.

[82] A. Mazahery and M. Ostad Shabani, "Mechanical properties of squeeze-cast A356 composites reinforced with $\mathrm{B}_{4} \mathrm{C}$ particulates," Journal of Materials Engineering and Performance, vol. 21, no. 2, pp. 247-252, 2012.

[83] S. Mallik, N. Ekere, C. Best, and R. Bhatti, "Investigation of thermal management materials for automotive electronic control units," Applied Thermal Engineering, vol. 31, no. 2-3, pp. 355-362, 2011.

[84] N. Altinkok, "Microstructure and tensile strength properties of aluminium alloys composites produced by pressureassisted aluminium infiltration of $\mathrm{Al}_{2} \mathrm{O}_{3} / \mathrm{SiC}$ preforms," Journal of Composite Materials, vol. 38, no. 17, pp. 15331543, 2004.

[85] L. A. Dobrzański, M. Kremzer, and M. Adamiak, "Manufacturing of aluminium matrix composite materials reinforced definition by $\mathrm{Al}_{2} \mathrm{O}_{3}$ particles," Journal of Achievements in Materials and Manufacturing, vol. 27, no. 1, pp. 99-102, 2008.

[86] S. Aksöz, O. Bican, R. Çalın, and B. Bostan, "Effect of T7 heat treatment on the dry sliding friction and wear properties of the SiC-reinforced AA 2014 aluminium matrix composites 
produced by vacuum infiltration," Proceedings of the Institution of Mechanical Engineers, Part J: Journal of Engineering Tribology, vol. 228, no. 3, pp. 312-319, 2014.

[87] M. Thünemann, O. Beffort, S. Kleiner, and U. Vogt, “Aluminum matrix composites based on preceramic-polymerbonded SiC preforms," Composites Science and Technology, vol. 67, no. 11-12, pp. 2377-2383, 2007.

[88] O. Bican, "Trees Microstructural, mechanical and dry sliding wear properties of the $\mathrm{MgO}$ reinforced aluminium matrix composites produced by vacuum infiltration," Kovove Materialy, vol. 52, no. 2, pp. 77-83, 2014.

[89] M. Sánchez, J. Rams, and A. Ureña, "Fabrication of aluminium composites reinforced with carbon fibres by a centrifugal infiltration process," Composites Part A: Applied Science and Manufacturing, vol. 41, no. 11, pp. 1605-1611, 2010.

[90] P. K. Rohatgi, J. K. Kim, N. Gupta, S. Alaraj, and A. Daoud, "Compressive characteristics of A356/fly ash cenosphere composites synthesized by pressure infiltration technique," Composites Part A: Applied Science and Manufacturing, vol. 37, no. 3, pp. 430-437, 2006.

[91] I. N. Orbulov, "Compressive properties of aluminium matrix syntactic foams," Materials Science and Engineering: A, vol. 555, pp. 52-56, 2012.

[92] Y. Wu, "Spray-atomized and codeposited $6061 \mathrm{Al} / \mathrm{SiCp}$ composites," JOM, vol. 555, pp. 16-23, 1991.

[93] N. Rajesh Jesudoss Hynes, R. Kumar, R. Tharmaraj, and P. Shenbaga Velu, "Production of aluminium metal matrix composites by liquid processing methods," AIP Conference Proceedings, vol. 1728, 2016.

[94] V. C. Srivastava and S. N. Ojha, "Microstructure and electrical conductivity of Al-SiCp composites produced by spray forming process," Bulletin of Materials Science, vol. 28, no. 2, pp. 125-130, 2005.

[95] V. C. Srivastava, A. Schneider, V. Uhlenwinkel, and K. Bauckhage, "Spray processing of $2014-\mathrm{Al}+\mathrm{SiCp}$ composites and their property evaluation," Materials Science and Engineering: A, vol. 412, no. 1-2, pp. 19-26, 2005.

[96] C. Zhi-gang, C. Ding, C. Zhen-hua, and Z. Hao, "Densification of spray-deposited 8009Al/SiCp composite tubular billet," Materials and Manufacturing Processes, vol. 24, no. 5, pp. 564-569, 2009.

[97] Z. Gang, Z. Hua, D. Chen, Y. Qiang, and G. Chen, "Microstructural evolution and its effects on mechanical properties of spray deposited $\mathrm{SiCp} / 8009 \mathrm{Al}$ composites during secondary processing," Transactions of Nonferrous Metals Society of China, vol. 19, no. 5, pp. 1116-1120, 2009.

[98] W. Yuan, J. Zhang, C. Zhang, and Z. Chen, "Processing of ultra-high strength $\mathrm{SiCp} / \mathrm{Al}-\mathrm{Zn}-\mathrm{Mg}$-Cu composites," Journal of Materials Processing Technology, vol. 209, no. 7, pp. 3251-3255, 2009.

[99] M. Gupta, F. Mohamed, E. Lavernia, and T. S. Srivatsan, "Microstructural evolution and mechanical properties of $\mathrm{SiC} / \mathrm{Al}_{2} \mathrm{O}_{3}$ particulate-reinforced spray-deposited metalmatrix composites," Journal of Materials Science, vol. 28, no. 8, pp. 2245-2259, 1993.

[100] M. Q. Li and Y. Chen, "Superplastic deformation of SiCp/ $2024 \mathrm{Al}$ composite fabricated by spray atomization and codeposition," Journal of Materials Engineering and Performance, vol. 6, no. 5, pp. 664-666, 1997.

[101] J. Rodríguez, M. A. Garrido-Maneiro, P. Poza, and M. T. Gómez-del Río, "Determination of mechanical properties of aluminium matrix composites constituents,"
Materials Science and Engineering: A, vol. 437, no. 2, pp. 406-412, 2006.

[102] T. Peat, A. Galloway, A. Toumpis, P. McNutt, and N. Iqbal, "The erosion performance of particle reinforced metal matrix composite coatings produced by co-deposition cold gas dynamic spraying," Applied Surface Science, vol. 396, pp. 1623-1634, 2017.

[103] A. Mortensen, Concise Encyclopedia of Composite Materials, Andreas Mortensen, New York, NY, USA, 2nd edition, 2007.

[104] C. S. Ramesh, A. Ahamed, B. H. Channabasappa, and R. Keshavamurthy, "Development of $\mathrm{Al} 6063-\mathrm{TiB}_{2}$ in situ composites," Materials \& Design, vol. 31, no. 4, pp. 2230-2236, 2010.

[105] H. B. Michael Rajan, S. Ramabalan, I. Dinaharan, and S. J. Vijay, "Synthesis and characterization of in situ formed titanium diboride particulate reinforced AA7075 aluminum alloy cast composites," Materials \& Design, vol. 44, pp. 438-445, 2013.

[106] J. David Raja Selvam and I. Dinaharan, "In situ formation of $\mathrm{ZrB}_{2}$ particulates and their influence on microstructure and tensile behavior of AA7075 aluminum matrix composites," Engineering Science and Technology, an International Journal, vol. 20, no. 1, pp. 187-196, 2017.

[107] V. Mohanavel, M. Naveen Kumar, K. Mageshkumar, C. Jayasekar, N. Dineshbabu, and S. Udishkumar, "Mechanical behavior of in situ $\mathrm{ZrB}_{2} / \mathrm{AA} 2014$ composite produced by the exothermic salt-metal reaction technique," Materials Today: Proceedings, vol. 4, no. 2, pp. 3215-3221, 2017.

[108] K. J. Lijay, J. D. R. Selvam, I. Dinaharan, and S. J. Vijay, "Microstructure and mechanical properties characterization of AA6061/TiC aluminum matrix composites synthesized by in situ reaction of silicon carbide and potassium fluotitanate," Transactions of Nonferrous Metals Society of China, vol. 26, no. 7, pp. 1791-1800, 2016.

[109] I. Dinaharan, N. Murugan, and S. Parameswaran, "Influence of in situ formed $\mathrm{ZrB}_{2}$ particles on microstructure and mechanical properties of AA6061 metal matrix composites," Materials Science and Engineering: A, vol. 528, no. 18, pp. 5733-5740, 2011.

[110] G. S. Pradeep Kumar, P. G. Koppad, R. Keshavamurthy, and M. Alipour, "Microstructure and mechanical behaviour of in situ fabricated AA6061-TiC metal matrix composites," Archives of Civil and Mechanical Engineering, vol. 17, no. 3, pp. 535-544, 2017.

[111] R. Gupta, G. P. Chaudhari, and B. S. S. Daniel, "Strengthening mechanisms in ultrasonically processed aluminium matrix composite with in-situ $\mathrm{Al}_{3} \mathrm{Ti}$ by salt addition," Composites Part B: Engineering, vol. 140, 2018.

[112] Y. C. Feng, L. Geng, A. B. Li, and Z. Z. Zheng, "Fabrication and characteristics of in situ Al12W particles reinforced aluminum matrix composites by reaction sintering," $M a-$ terials \& Design, vol. 31, no. 2, pp. 965-967, 2010.

[113] B. Kaveendran, G. S. Wang, L. J. Huang, L. Geng, and H. X. Peng, "In situ $\left(\mathrm{Al}_{3} \mathrm{Zr}+\mathrm{Al}_{2} \mathrm{O}_{3} \mathrm{np}\right) / 2024 \mathrm{Al}$ metal matrix composite with novel reinforcement distributions fabricated by reaction hot pressing," Journal of Alloys and Compounds, vol. 581, pp. 16-22, 2013. 